\title{
BASES PARA UNA NUEVA HISTORIA DEL PATRIMONIO CULTURAL: UN ESTUDIO DE CASO EN SANTAFE DE BOGOTA ${ }^{1}$
}

\author{
Monika Therrien \\ Universidad de los Andes, Bogotá
}

\section{INTRODUCCION}

Los recientes proyectos de restauración en monumentos y del patrimonio urbano en general, se han convertido en otro recurso para la investigación histórica, que por su perspectiva interdisciplinaria (iconografía, historia, arquitectura o arqueología) permiten obtener información que no se sustenta en una única fuente de datos (estilos y tipos edilicios, pintura mural, documentos o material cultural) y pueden llegar, de esta manera, a resultados basados en el contraste más que en la

1 Este documento hace parte de los resultados del estudio arqueológico-historico efectuado en la "La Casa de los Comuneros II". en el marco de la obra de restauración que pondrá el edificio al servicio del Instituto Distrital de Cultura y Turismo (IDCT), Bogotá. Agradezco al arquitecto Tomás Castrillón por incluirme en el equipo de trabajo integrado para tal fin, así como a la empresa Estructuras de Hormigón Ltda. Este estudio habría sido imposible adelantarlo sin la colaboración de tres futuras arqueólogas: Silvana Bonfante, Marta Fandiño y Jimena Lobo Guerrero, quienes participaron en todas las etapas de la investigación. 
supremacía de una disciplina. Aunque en la mayoría de los casos la declaratoria de monumentos se esgrimió desde pequeños y selectos grupos de la élite, de acuerdo con sus propios intereses (políticos, intelectuales o culturales) y como soporte para legitimarse a sí mismos, el carácter interdisciplinario de los actuales estudios de los monumentos le resta fuerza a los argumentos que asocian a estos bienes, y a la mayor parte del patrimonio histórico, con un sector hegemónico de la sociedad de cierta época. Con las distintas perspectivas disciplinarias es posible recuperar tras el patrimonio, no sólo la historia de los "personajes" o grupos dominantes, sino de aquello que fue excluido o desconocido, las huellas de los que dejaron su rastro en otro tipo de evidencias materiales, como se mostrará en el presente estudio histórico, arqueológico y arquitectónico.

Este ensayo hace parte de una investigación más amplia elaborada en el transcurso de la restauración de la "Casa de los Comuneros II". ${ }^{2}$ El concepto de restauración empleado en esta investigación abarca, más allá del objetivo de restituir físicamente el monumento, la recuperación de la historia social y cultural de un sector específico de la ciudad para la memoria colectiva, a partir de las evidencias materiales -culturales y constructivas-. Los resultados no son concluyentes, por el contrario, se pretende contribuir con un marco de contraste para los futuros datos obtenidos en la intervención de edificios que así lo ameriten. Esto permitirá generar información para el análisis comparativo y el avance en el conocimiento del desarrollo urbano de Bogotá, especialmente en cuanto a su cultura material.

Planteado de esta manera, la restauración física del edificio no depende únicamente de las observaciones formales y estilísticas que se hacen desde el presente. Por el contrario, se aportan datos históricos y arqueológicos contrastantes, que permiten sustentar las decisiones que finalmente se tomen para la adecuación y puesta en valor del inmueble. En esta medida es posible combinar el diseño final, que busca la satisfacción de las

2 Ubicada sobre la carrera octava con calle décima. El propósito es incorporarla a la casa del Instituto Distrital de Cultura y Turismo -IDCT- (esquina suroccidental de la carrera octava con calle décima), en Santafé de Bogotá. 
necesidades y usos actuales que debe brindar la casa, con los diversos significados y funciones que tuvo en el pasado. ${ }^{3}$

En este sentido, la aproximación al conocimiento del pasado, tiene por objeto recolectar las evidencias que permitan identificar a través de los vestigios arqueológicos, arquitectónicos y documentales de la construcción y transformación de las edificaciones, cuál fue el significado, en su uso y función, que tuvieron los inmuebles para los moradores y/o propietarios. Más que la exigencia e implantación directa de las políticas urbanas establecidas por las autoridades, se propone que fueron las exigencias sociales y/o culturales, aunadas a las posibilidades económicas de los propietarios, las que finalmente contribuyeron a darle el aspecto final a sus viviendas o inmuebles, así como a las modificaciones posteriores. Las respuestas posibles a estas exigencias, se enmarcan dentro del contexto más amplio de la estructura social en el ámbito de la ciudad.

Culturalmente, la ciudad de Santafé de Bogotá, se debatía entre una población española minoritaria y una numerosa población indígena (siglos XVI-XVII). Como resultado de la convivencia entre ellos, con el paso de los siglos, se derivaron los diversos tipos de mestizos -castas-. Esto parece que de alguna manera reforzó ciertas costumbres y hábitos, dirigidas a hacer manifiesta la diferenciación social entre los distintos grupos. La cohabitación cercana de españoles con indios en Santafé al comienzo de la época colonial, y luego con los mestizos, se convirtió en escenario de diferencias materiales en el vestido, la vivienda, la alimentación, las celebraciones así como en las expresiones lingüísticas, con lo cual se buscó consolidar los mecanismos de identificación social y cultural de los individuos, especialmente de la élite que quería "distinguirse".

3 Esto bien lo señala Carandini (Historias en la Tierra, Barcelona, Editorial Crítica, 1997, p. 21) "Un monumento puede ser tomado legítimamente en consideración desde el punto de vista histórico-anticuario, prefiriendo la tradición literaria (textos, inscripciones, monedas) a la lectura analítica de la realidad material... También es respetable tomar en consideración un monumento desde el único punto de vista de su decoración arquitectónica. Mosaicos, pinturas, capiteles, arquitrabes y estucos tienen sus tipologías, su historia interna, que es esencial para comprender la mentalidad de los constructores de aquellos edificios... Solamente la toma en consideración conjunta de todos estos puntos de vista, sin considerar aquella en que se está más especializado como la más importante, permite esperar acercarse a la verdad de un monumento... Bienvenidos sean por lo tanto los estudios histórico-anticuarios, iconográficos y tipológicos de cualquier tipo, pero la lectura histórico-estructural de un monumento no puede prescindir de las lógicas estratigráficas". 
Se pretende en el marco de la historia del patrimonio urbano, y en la restauración de sus monumentos, recuperar esos procesos sociales configurados a partir de las relaciones entre diferentes grupos. En el análisis e interpretación de la información recuperada de la Casa de los Comuneros II, la cultura material es entendida como un producto de estas relaciones y procesos. ${ }^{4}$

\section{LA CIUDAD COMO RUPTURA DE MODELOS DE HABITO}

Es probable que los estudios sobre la ciudad y, en especial, el modelo de ciudad colonial, sea actualmente una casi inagotable fuente bibliográfica, cuando en los albores del nuevo milenio ésta se ha convertido en un escenario casi exclusivo de vida.

La ciudad damero, ${ }^{5}$ aunque concebida en el seno de Europa, pretendía ser expresada en su integridad en América, donde ya existían otros modelos urbanos (en México o Perú). El nuevo mundo presentó amplias opciones para implantar la ciudad "modelo", mientras que en el viejo continente ésta debía competir y reemplazar los ordenamientos medievales y/o moriscos existentes.

No se quiere discutir aquí las múltiples definiciones que de ella se han elaborado, ni las perspectivas que se han desprendido de su estudio. Se pretende construir la noción de ciudad como una expresión material del contexto en el cual se propicia el contacto humano y como el instrumento que configura las relaciones sociales y culturales entre los distintos grupos que pretende albergar. Para ello se ha tomado a la zona de contacto como el espacio de encuentros coloniales, el espacio en el cual gentes geográfica e históricamente separadas entran en contacto entre sí y establecen relaciones continuas, que involucran usualmente condiciones de coerción, desigualdad radical y conflictos inmanejables. ${ }^{6}$

4 La noción de cultura material usada se retoma de la definición dada por Deetz (In Small Things Forgotten, Nueva York, Anchor Books, 1996, p. 35): "La cultura material... no es cultura sino su producto. La cultura son las reglas de comportamiento socialmente transmitidas, las maneras de pensar y de hacer las cosas... La cultura material usualmente se considera como algo sinónimo a los artefactos, el vasto universo de objetos usados por la especie humana para apropiarse del mundo físico, para facilitar la interacción social y benefi ciar nuestro estado mental. Una definición algo más amplia de la cultura material, útil para enfatizar qué tan profundamente nuestro mundo es el producto de nuestros pensamientos, sería la de ese sector de nuestro entorno físico que nosotros modificamos a través del comportamiento determinado culturalmente." (cursi vas del autor, traducción mía).

Se refiere a las ciudades que están constituidas por retículas, cuadradas o rectangulares.

6 Mary Louise Pratt, Imperial Writing. Travel Writing and Transculturation, Londres, Routledge, 1992, pp. 67, traducción mía. 
Así la ciudad adquiere un carácter más allá de lo convencional: no es la imposición de un modelo de dominio. Además de ser el ámbito de sometimiento y dominación también es el espacio donde se improvisan y se negocian estas relaciones.

El modelo "ideal" del damero emulaba el modelo "ideal" de sociedad: en la punta de la pirámide de la estructura social y política estaban los representantes del poder real y el eclesiástico. La expresión material de esta disposición en la ciudad se dió de preferencia alrededor de la Plaza Mayor: descrita por Lomné como un auténtico escenario donde se verificaron "ceremonias de la información", en el cual los vecinos sellaron el pacto explícito de su adhesión al estandarte de la Fe y al pendón real. ${ }^{7}$ Desde la punta se irradiaba hacia las bases de la pirámide (atravesando las distintas escalas de la sociedad) el orden social, la moral, la justicia, los hábitos y costumbres, es decir, desde la plaza -lugar de contacto y comunicación- hacia los diversos pobladores ubicados en los alrededores del núcleo hasta las márgenes de la ciudad, constituidas éstas últimas por los sectores más pobres.

Sin embargo, al tratarse la ciudad del nuevo mundo como una zona de contacto -tal como se ha definido aquí- con sus diferentes funciones (centro ceremonial, centro de abastecimiento, centro de comunicación), habitada y frecuentada por grupos étnicos y sociales distintos, es posible observar en ella, más que el flujo unidireccional de normas y hábitos, las rupturas en el modelo "ideal" de ciudad-sociedad.

La ciudad como tal, las edificaciones, calles y plazas que la componen, son los recursos culturales materiales a través de los cuales se indaga sobre sus moradores, ya no con la mirada desde el grupo hegemónico -de ayer y de hoy-, sino como la expresión de las relaciones horizontales y verticales multidireccionales de la sociedad, en la continua pugna por identificarse cada grupo en ella así como la ciudad misma.

Este será un primer intento de mirar así a la ciudad, en el tiempo como en el espacio.

Georges Lomné, "Las ciudades de la Nueva Granada: teatro y objeto de los conflictos de la memoria política (1810-1830)", Anuario Colombiano de Historia Social y de la Cultura, No. 21, 1993, p. 114. Igualmente. Aprile-Gniset se refiere a ella como "un lugar excepcional y sacralizado como tal: sede del prestigio, de la autoridad y la justicia, recinto de los rituales sagrados y de la solemnidad" La ciudad colombiana. Prehispánica, de conquista e indiana, Bogotá, Biblioteca Banco Popular, 1991, pp. 196. 


\section{EL CONTRASTE INTERDISCIPLINARIO}

\section{Metodología}

Se ha discutido que el estudio del patrimonio urbano actualmente constituye un recurso interesante, por el cual se pueden evaluar los aportes que se producen al conocimiento sobre la historia de la ciudad, mediante el contraste de los resultados obtenidos de las distintas fuentes de información con las cuales se trabaja. Sin embargo, en los proyectos de restauración de bienes inmuebles existe una tendencia generalizada a someter la recolección de los datos arquitectónicos, arqueológicos, históricos e iconográficos, para justificar el carácter monumental del bien. Sin embargo, con preguntas dirigidas a explicar su significado, en el pasado y en el presente, este material constituye un apoyo para el análisis orientado a construir aspectos más amplios (en este caso el de la ciudad) en los cuales se genera y se recrea el patrimonio.

El estudio de la "Casa de los Comuneros II", constituye un intento de implementar este análisis. Hacia el futuro, el objetivo será el de lograr aunar mayor información de otros proyectos similares, efectuados en Bogotá, y así construir la noción de ciudad como zona de contacto y, a la vez, utilizar el recurso del contraste de las fuentes, más que depender del discurso hegemónico de una sola. La herramienta conceptual metodológica que permite atravesar las diferentes informaciones es la de cultura material, entendida como la representación de la ideología de la sociedad en la creación, uso, transformación o destrucción de los recursos físicos (incluso el del lenguaje). ${ }^{8}$

\section{El método estratigráfico}

Las nociones sobre ciudad y el rol de sus habitantes son las que modelan la metodología seguida en el estudio, en la cual se privilegia el método estratigráfico como una herramienta que permite observar las características del edificio y de sus ocupantes de manera horizontal (en el espacio) y de manera vertical (en el tiempo). El análisis de los materiales culturales así como el contraste de los datos históricos y arquitectónicos son los que,

\footnotetext{
8 James Deetz, In Small Things Forgotten, Nueva York, Anchor Books, 1996.
} 
finalmente, permiten reconstruir las configuraciones sociales desarrolladas en los diferentes períodos de ocupación estudiados, y abren una ventana para el estudio multidisciplinario de los inmuebles.

Para llegar a conocer a través de la arqueología cuándo y cómo ocurren los cambios dentro de un proceso histórico social, se recurre al método estratigráfico como la herramienta principal de análisis. ${ }^{9}$ Este se implemento mediante la excavación de sondeos, trincheras o excavaciones en áreas, dependiendo de las características y objetivos del proyecto. En casos como las exploraciones arqueológicas de monumentos o inmuebles, el método resulta inevitable para comprender la evolución de los espacios y en lo posible identificar las funciones de los mismos.

El proceso de generación de estratos, que permite hacer la lectura de las actividades humanas es el resultado de "1) erosión / destrucción, 2) movimiento / transporte, 3) deposición / acumulación... de fuerzas naturales y humanas...". ${ }^{10}$ Los estratos se reconocen por características tales como poseer una superficie, la cual está delimitada en un área y tiene relieve, tener una posición respecto al espacio y el tiempo, de acuerdo a sus relaciones con los demás estratos y estar compuesto por unos materiales específicos. ${ }^{11}$ Bajo estos principios se reconstruye la secuencia estratigráfica, a partir de las relaciones de contemporaneidad, de sucesión y las inexistentes. El principio básico que sustenta la interpretación de la secuencia es que cualquier estrato que sucede a otro siempre será posterior en tiempo (a menos que se detecte una intrusión). Una mayor precisión en la cronología se obtiene a partir del material constructivo o cultural más moderno que contenga el estrato identificado.

Los sondeos para recuperar la información sobre el cambio en el inmueble se denominaron unidades de excavación (UE), por cuanto son la mínima unidad significativa de información arqueológica. En el caso de la "Casa de los Comuneros II", estas unidades no pudieron efectuarse de manera regu-

9 Sobre los principios del método estratigráfico ver Andrea Carandini, Historias en la Tierra, Barcelona, Editorial Crítica, 1997 y Eward Harris, Principios de estratigrafía arqueológica, Barcelona, Editorial Críti ca, 1991.

10 Carandini, Historias en la Tierra, pp. 31.

${ }^{11}$ Ibid, p. 37, para detalles más específicos. Los estratos se diferenciaron por tres criterios: textura, coloración y el contenido del material cultural o constructivo. 
lar, con las mismas dimensiones y con una ubicación recurrente en cada uno de los espacios del inmueble, por cuanto el estudio arqueológico se realizó de manera paralela con la intervención, lo cual en ocasiones dificultó dicha tarea. Las malas condiciones de los suelos y de la edificación en sí, impidieron realizar excavaciones en área para hallar otras estructuras profundas, pues se temió afectar estructuralmente el inmueble. Generalmente se realizaron pequeños sondeos y sólo se ampliaron cuando las evidencias lo ameritaron.

\section{Los materiales arqueológicos}

La reconstrucción de la secuencia estratigráfica sin el análisis de los materiales culturales puede redundar en un trabajo árido, en el que sólo se describe la estructura del inmueble sin contar con otros elementos de referencia de sus moradores y/o propietarios. Los materiales arqueológicos, además de auxiliar en la datación de los estratos identificados, son la fuente que permiten aproximarse a los individuos que los utilizaron y desecharon.

Con el objeto de imprimirle esta dinámica a los bienes "inmuebles", es indispensable incorporar el análisis de los materiales culturales incluidos dentro de ellos. ¿Cómo llegaron al lugar los objetos encontrados? ¿Qué posibles usos se les dieron? Son algunas de las inquietudes que conducen a interpretar el significado de los objetos excavados. En el caso de la exploración de inmuebles se debe tener certeza de que los materiales corresponden a aquellas actividades que se describen. Por esto, es determinante establecer el contexto y las condiciones de deposición de los materiales, para ofrecer una seguridad en la interpretación de la secuencia estratigráfica.

¿Es posible reconocer social y culturalmente a los miembros de la sociedad a quienes les pertenecieron? ¿Se pueden identificar las actividades que se desarrollaron en el tiempo y en el espacio a través de la cultura material? Son algunas de las preguntas que conducen a recoger y analizar, de manera cuidadosa los distintos objetos hallados a lo largo de las excavaciones. En este caso, con cada balde de tierra extraído se pudo recolectar suficiente información para conocer algunos aspectos de la vida de los ocupantes del predio.

Los materiales se dividieron en dos: 1) los constructivos, compuestos por ladrillos, tejas, piedras, pañetes, clavos, puntillas. 2) los culturales, compuestos por materiales plásticos (botones, empaques), vidrios, cerámicas, 


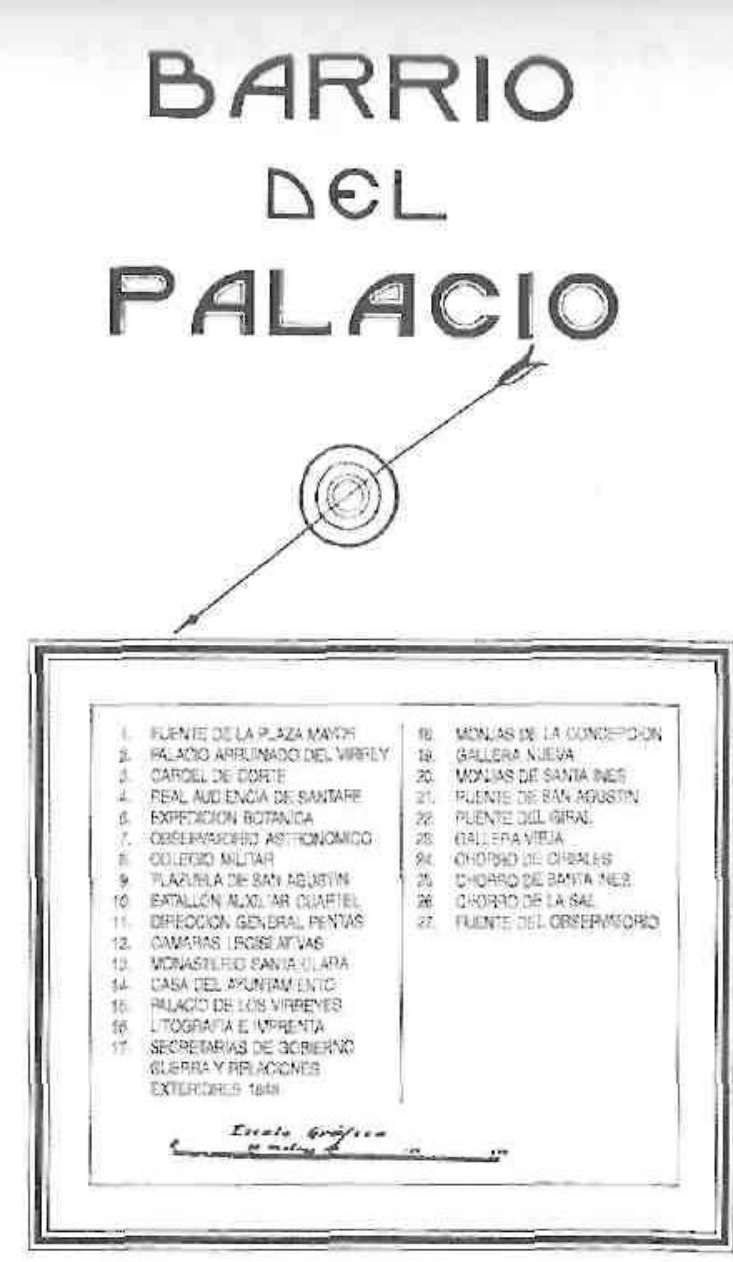

Figura 1. Tomado de De la Rosa (1938)

* Casa de los Comuneros

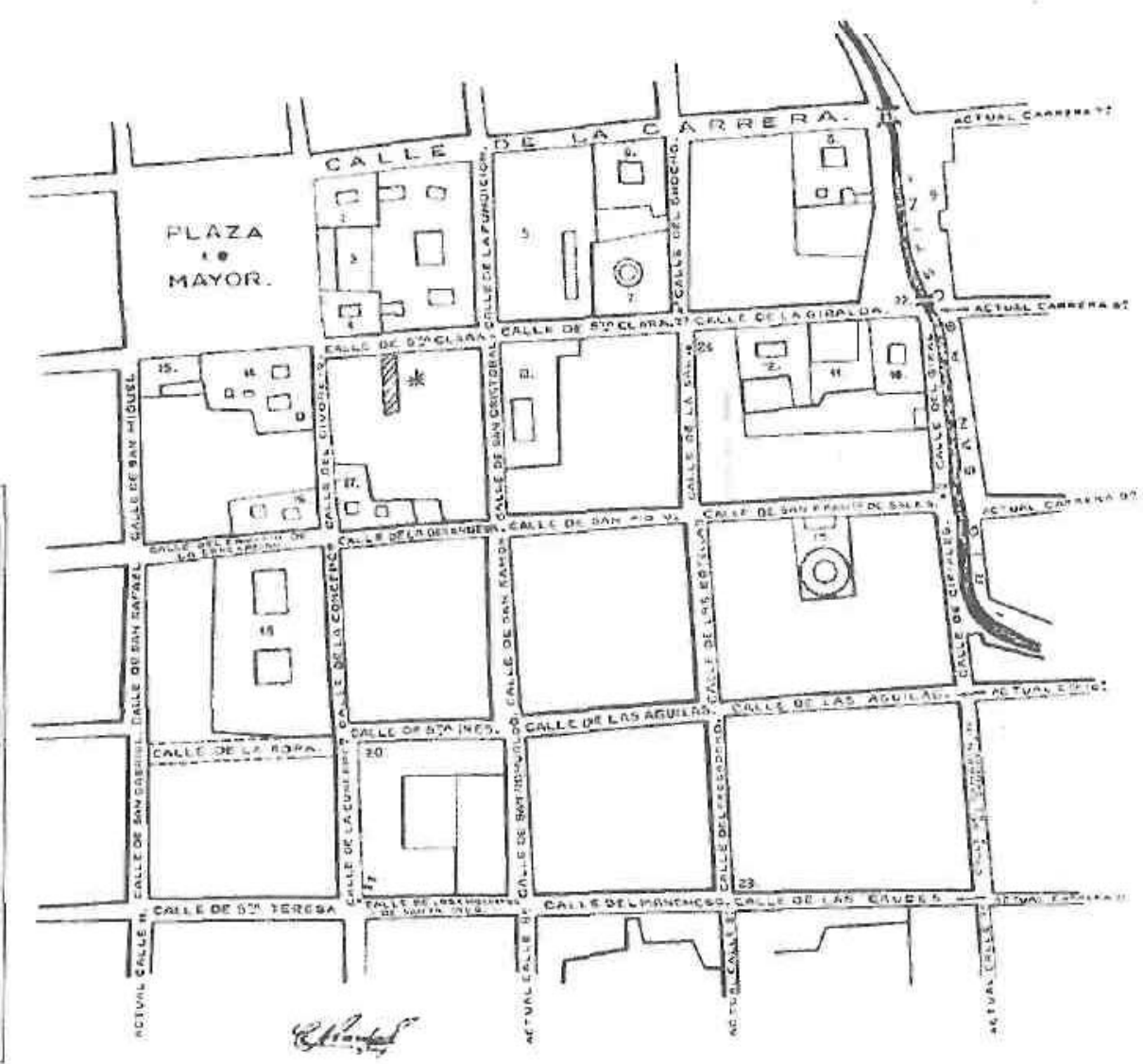


huesos de animales, tela, cuero y metálicos (tapas). Igualmente, se tomaron muestras de suelo de los niveles más antiguos para identificar macrorrestos de plantas, tanto para el consumo de alimentos como de las ornamentales que posiblemente estuvieran sembradas en los patios y las huertas.

\section{El análisis documental}

Como herramienta de contraste para la interpretación de los datos arqueológicos recuperados, es esencial contar con el registro documental. Se enfatiza el carácter comparativo que deben tener los resultados de una y otra investigación, de esta manera se ejerce algún control sobre la interpretación que se hace desde el presente sobre aspectos relacionados con el pasado. En cuanto a la lectura de los textos de fuentes primarias, se debe conocer y entender el ambiente de la época en la cual fueron escritos y analizarlos desde esta óptica; existen diversos intereses, prejuicios u omisiones que deben ponerse de relieve. Esta ha sido la tarea del análisis de los textos consultados, con los cuales se restauró no únicamente la "Casa de los Comuneros", sino su entorno inmediato.

Los datos que recogen la historia de Bogotá y el área circundante al sitio investigado se tomaron de aquellos documentos en que se hiciera referencia a la distribución urbana de la ciudad, así como a las principales actividades que se desarrollaron en los alrededores de la "Casa de los Comuneros II" específicamente. Con este objeto se consultaron varios libros cronológicamente más recientes ${ }^{12}$ y de estos hacia atrás, las crónicas de bogotanos de finales del siglo XIX y principios del XX, ${ }^{13}$ así como las de los viajeros extranjeros del siglo XIX ${ }^{14}$. Toda esta información se cotejó con los mapas de la ciudad y con bibliografía más reciente que se funda-

12 El análisis se basó esencialmente en los textos de Carlos Martínez, Santafé. Capital del Nuevo Reino de Granada, Bogotá, Fondo de Promoción de la Cultura, 1988. Alfredo Ortega Díaz, Arquitectura de Bogotá, Bogotá, Proa, 1988 11924] y, Enrique Ortega Ricaurte, Testamento de don Juan Flórez de Ocáriz, Boletín de Historia y Antigüedades, vol. XV, 1940.

13 Con ayuda de los textos de Pedro M. Ibañez, Crónicas de Bogotá. Tomo IV, Bogotá, Academia de Historia de Bogotá, Tercer Mundo, 1989 [1951]. Ricardo Silva, "El remiendito", Cuadros de Costumbres, Cali, Carvajal y Cía., 1969 [c. 1860] y José María Cordovez Moure, Reminiscencias de Santafé y Bogotá, 6 tomos, Bogotá, Gerardo Rivas (ed.), 1991 [1893-1900].

14 Gaspard T. Mollien, Viaje por la República de Colombia en 1823, Bogotá, Banco de la República, 1992. Stuart Cochrane, Viajes por Colombia, 1823-1824, Bogotá, Banco de la República, 1994 [1825]. Isaac Holton, La Nueva Granada. Veinte meses en los Andes, Bogotá, Banco de la República, 1981 [1857], 


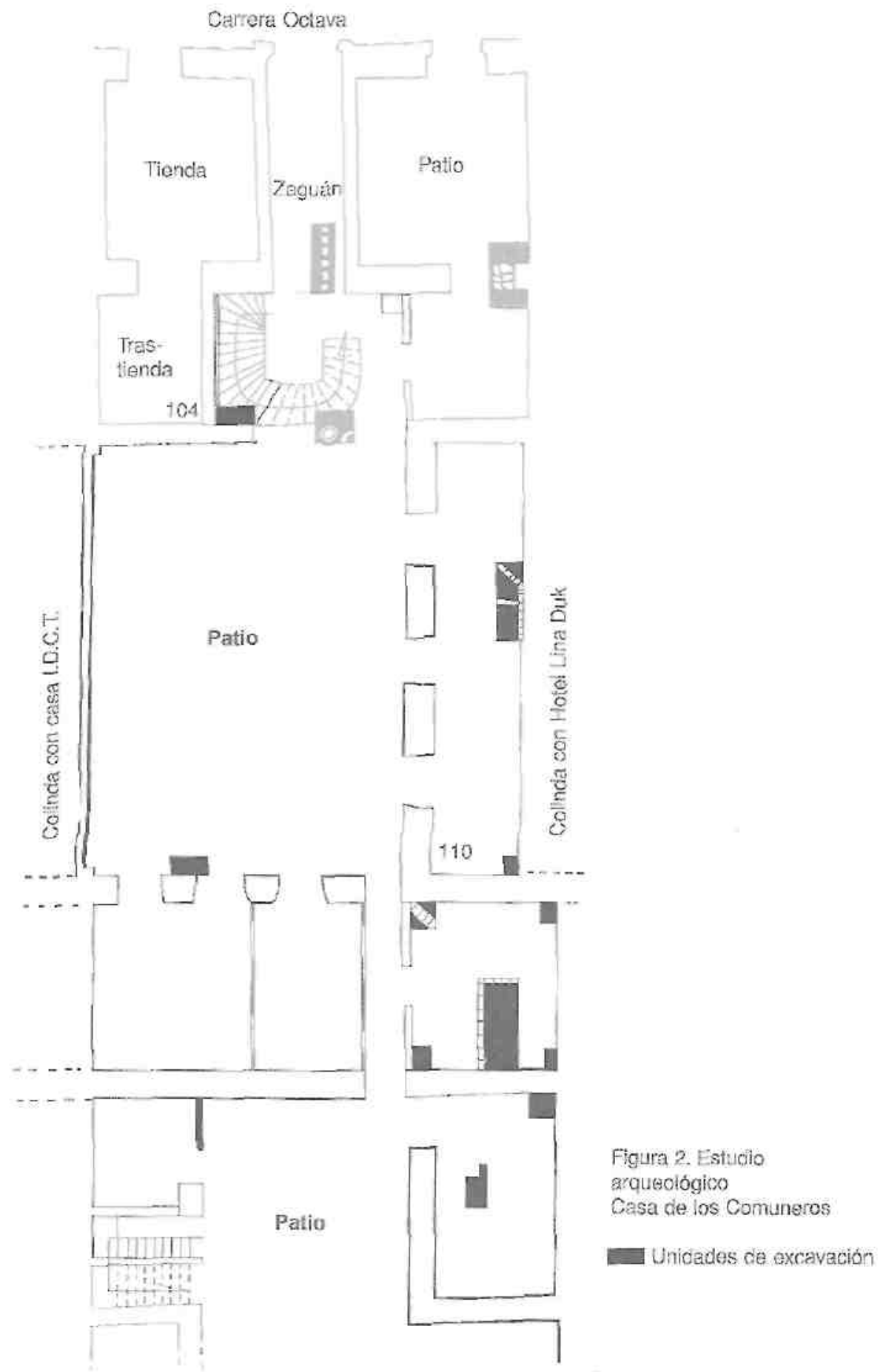


menta en fuentes primarias. ${ }^{15}$ Para el período colonial se hizo un análisis más exhaustivo de la transcripción del testamento de Flórez de Ocáriz quien habitó durante el siglo XVII el predio donde se ubica la casa. ${ }^{16}$

\section{"Sucedió en una calle"}

Los resultados del estudio que a continuación se presentan, siguen un orden cronológico, de acuerdo a las ocupaciones puestas en evidencia. Sin embargo, para comprender el significado de las estructuras y materiales hallados, se inicia cada período con una presentación general y breve de la ciudad, que luego se hace más específica hasta detallar el sitio investigado. La interpretación sigue los lincamientos metodológicos expuestos y se presentan en este orden.

Se considera que existen dos aspectos fundamentales para lograr interpretar la evolución del predio de la "Casa de los Comuneros II", uno de ellos es el de identificar secuencialmente las distintas denominaciones que tuvieron tanto la calle donde se localiza la Casa como las circundantes. Por esto se presenta de manera esquemática la evolución de la nomenclatura. ${ }^{17}$ De igual manera, es preciso identificar el carácter de las actividades desarrolladas a su alrededor y las implicaciones que esto pudo tener en el eje evolutivo de la casa.

\section{COLONIA}

\section{Generalidades}

Según narra Flórez de Ocáriz en sus Genealogías, ${ }^{18}$ en 1672 la ciudad de Santafé contaba con aproximadamente 3.000 vecinos (españoles) en la ciudad y 10.000 indios dentro de ella así como en los alrededores (en Pueblo Viejo y Pueblo Nuevo).

\footnotetext{
${ }^{15}$ Fundación Misión Colombia, Historia de Bogotá, Tomos I y II, Bogotá, Editorial Villegas, 1988 y Julián Vargas Lesmes, La sociedad de Santa Fé Colonial, Bogotá, CINEP, 1990.

${ }^{16}$ Transcripción de Enrique Ortega Ricaurte, Boletín de Historia y Antigüedades, vol 30.

${ }^{17}$ Estos datos se tomaron de: Moisés De la Rosa, Calles de Santafé de Bogotá, Bogotá, Ediciones del Concejo, 1938; Historia de Bogotá, 1988, Tomo 2 y, Pedro M. Ibañez, Crónicas de Bogotá, 1989.

${ }^{18}$ Boletín de Historia y Antigüedades, 1925, vol. 12.
} 
El eje principal de desarrollo de la ciudad se estableció entre la plaza de las Hierbas (hoy Plaza de Santander), en la que se fundaron los primeros conventos y las casas "más principales", y la Plaza Mayor donde se establecieron la Catedral y la Real Audiencia. A partir de la segunda mitad del siglo XVII se terminó de configurar la ciudad, y permaneció así a lo largo de todo el siglo XVIII, cuando para unos aparenta encontrarse estancada, ${ }^{19}$ sin embargo, otros consideran que es un período en que por fin se consolidan en suelo americano las instituciones y el ordenamiento del régimen colonial. ${ }^{20}$

\section{El barrio del Palacio}

El terreno de la "Casa de los Comuneros" se localizó, en la época colonial, sobre la calle de Santa Clara, llamada así formalmente en 1770. Según de la Rosa, ${ }^{21}$ la calle de Santa Clara perteneció "al barrio del Palacio, uno de los cuatro en que se subdividió el feligresado o parroquia de la Catedral", dato que a su vez él tomó de la "Instrucción para el Gobierno de los Alcaldes de Barrio de Santafé de Bogotá", de noviembre 10 de 1774. En general, todos los barrios de Santafé correspondían a las parroquias erigidas en la ciudad i aún hoy), es así que existe la correspondencia entre el barrio o parroquia de las Nieves, el de Santa Bárbara, el de Egipto, etc. No obstante esta especificidad durante la Colonia y, aún después, en la República, el barrio del Palacio, donde se encuentra ubicada la "Casa de los Comuneros II", así como el de la Catedral, el Príncipe y de San Jorge fueron más conocidos como el barrio conjunto de la Catedral (hoy parte de La Candelaria).

En el período colonial, las manzanas alrededor de la "Casa de los Comuneros" eran pocas, por cuanto, como se mencionó, la mayor parte de las actividades se concentraban en las cuadras contiguas a la Catedral Mayor y hacia el oriente. De la zona en cuestión se destaca el edificio de la Real Audiencia, cuya construcción se inició sobre el costado sur de la Plaza Mayor después de 1555, fecha en la cual se dio la orden de trasladar allí el mercado desde la Plaza de las Hierbas, la cual tuvo hasta ese momento mayor preeminencia. ${ }^{22}$ En el costado occidental de la plaza existieron va-

\footnotetext{
${ }^{19}$ Julián Vargas Lesmes, La Sociedad de Santa Fé Colonial, pp. $\quad{ }^{20}$ 3-5. Kathleen Deagan, Historical Archaeology, vol. 3, $1998 . \quad \quad \quad{ }^{21}$ Moisés De la Rosa, Calles de Santafé de Bogotá, pp. 138-140. $\quad{ }^{22}$ Carlos Martínez, Capital del Nuevo Reino de Granada, p. 258.
} 
rios edificios, entre los cuales estaban la cárcel chiquita y la casa del Cabildo (o Ayuntamiento), hacia el sector sur.

Otros edificios notables fueron los conventos que rodearon la casa, los cuales eran todos femeninos, mientras que los de hombres se ubicaron preferencialmente en el eje de la calle Real o hacia arriba. En el sector se encontraban el convento de la Concepción, segundo en antigüedad después del de San Francisco el cual se termina de construir en 1595 y ocupa dos manzanas; el de Santa Clara, cuya construcción termina en 1630 y para 1696 cuenta con más de cien monjas y, por último, el de Santa Inés, el cual se construye a partir de 1638 y sólo se termina muchos años después. En el mismo barrio, ya al final de la Colonia, se funda en 1770 el Colegio de San Nicolás de Bari, pero es poco lo que dura.

Inmediatamente enfrente de la "Casa de los Comuneros II" (parte posterior del edificio de la Audiencia), al parecer existía un solar semivacío, en el gráfico de De la Rosa (1938:138) aparece con unas pequeñas construcciones hacia el interior del solar. En dirección sur por la calle de Santa Clara, aparentemente el sector contenía pocos edificios, de estos sólo se destaca el convento que dio su nombre a la calle y el chorro de la sal, ubicado en la calle del mismo nombre. Por otra parte, en la dirección oriente-occidente, en las calles de la Concepción y del Divorcio pareciera existir mayor actividad ya que sobre ellas estaban los otros dos conventos mencionados.

El comercio y las procesiones religiosas, eventos importantes dentro de la vida cotidiana de la ciudad, tuvieron lugar en la calle Real y de la Carrera (hoy carrera 7a.). En la Plaza Mayor, alrededor de 1585, se instaló una pila de agua, de la cual podían surtirse del líquido los vecinos, además, que debía resultar práctica para los días de mercado que también se efectuaban en esta plaza. Sólo hasta el siglo pasado se trasladó de sitio la plaza de mercado, a la huerta que era de las religiosas de la Concepción, donde se construye un mercado cubierto (de ahí que a esta calle también se le conociera como la calle del Mercado).

Varios acontecimientos alteraron la ciudad y el entorno de la "Casa de los Comuneros II", entre ellos los dos terremotos de fines de siglo. El de 1743 ocasionó varios daños que se agravaron con el de 1785, entre otros el del edificio proyectado como sede de los virreyes, localizado en la esquina oriental del costado sur de la Plaza, que en 1786 un incendio lo devastó totalmente y se instaló, entonces, en el costado occidental de la plaza, en la esquina norte. 
En conclusión, probablemente el eje de importancia de este sector del barrio Je la Catedral (o del Palacio), estaría enfocado principalmente entre la Plaza Mayor y los conventos de la Concepción y de Santa Inés. Esto conduciría a pensar que la evolución espacial de la manzana ubicada sobre este eje, así como la orientación en el uso y función de las casas edificadas en ella, se recargó hacia la calle del Divorcio, más que sobre la calle de Santa Clara.

\section{"Casa de los Comuneros" ¿Cómo identificar el eje evolutivo de la casa?}

Como se mencionó, el estudio arqueológico analiza los factores internos y externos -económicos, sociales, políticos y naturales- que posiblemente incidieron en la construcción y las posteriores modificaciones de la vivienda; en este caso, la traza urbana es uno de esos factores que debe examinarse. En Santafé corresponde a la "traza limeña"23 con la iglesia catedral en dirección levante-poniente, y en la cual las manzanas originalmente se sub-dividen en cuatro solares. Idealmente se concibió que el paso siguiente en la densificación de estos solares se siguiera en un sólo sentido, ${ }^{24}$ subdivi-diendo el solar en dirección oriente a occidente o de norte-sur. Al parecer, este último caso se dio en Bogotá como se plantea en la investigación histórica de la "Casa de los Comuneros II". ${ }^{25}$

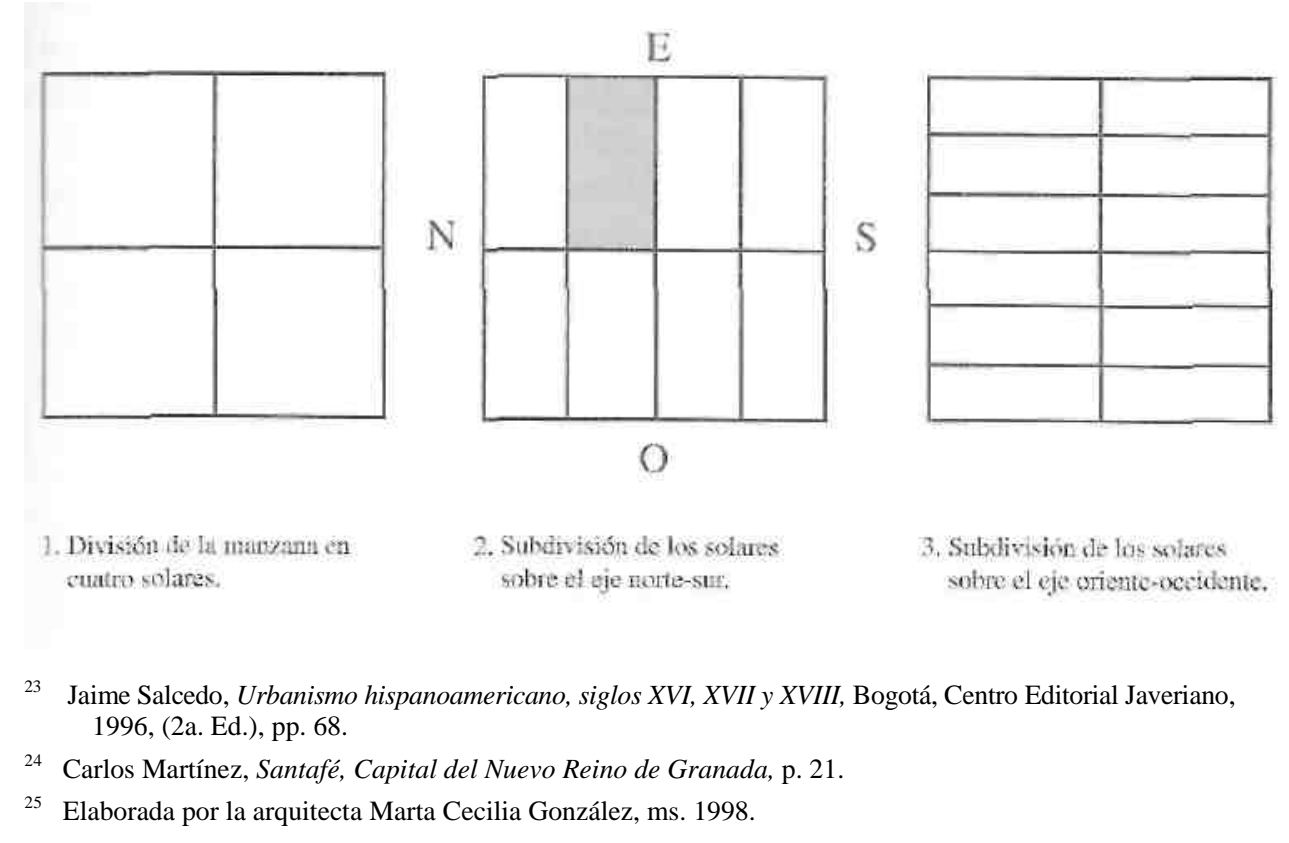


Actualmente, la casa corresponde a una de las subdivisiones hechas sobre el eje norte-sur y posee un marcado estilo republicano. El desarrollo de los espacios al interior de ella es en sentido oriente-occidente: su puerta principal se encuentra sobre la carrera 8a. mientras al fondo colinda con otra construcción. A cada lado de la entrada a la casa existe un espacio para una tienda (actualmente sólo funciona la del costado norte) y cada una, a su vez, cuenta con una trastienda. La entrada en sí consta de una primera puerta y luego de un zaguán también con puerta. Al traspasar este umbral, se llega a un corredor compuesto por arcos y columnas y hacia el costado norte está la escalera que conduce al segundo piso. A ésto sigue el primer patio, surcado al sur por diferentes espacios en el primer y segundo piso. Estos espacios y otros que se hallan en la parte posterior (hacia el occidente) del patio, conforman, a su vez, el corredor que conduce al segundo patio, el cual limita con el espacio de la casa construido más recientemente; el registro notarial señala que en 1943 se encontraba en construcción. ${ }^{26}$ Este traspatio se encuentra rodeado por el norte y sur con otra serie de espacios, entre ellos una escalera en el costado norte y los baños en el sur.

Con base en esta orientación y distribución se inició el estudio arqueológico, en el cual se planteaba encontrar, en la misma dirección, las evidencias de la evolución del inmueble desde la época Colonial. Inicialmente se esperó demostrar que el primer espacio construido se encontraba ubicado al oriente (sobre la carrera octava) luego, hacia el occidente, se irían construyendo los espacios más recientes. Sin embargo, en los sondeos arqueológicos, se hallaron evidencias de varias estructuras antiguas a lo largo de todo el predio, contrario a lo planteado. De otra parte, se demostró que los vestigios de los antiguos cimientos y muros de tapia de la Casa de los Comuneros II estaban conectados con los del predio aledaño, hoy casa del Instituto Distrital de Cultura y Turismo.

\section{Secuencia estratigráfica de la "Casa de los Comuneros"}

Con el objeto de identificar la morfología de la casa más antigua, se llegó en los sondeos arqueológicos hasta la base de la misma. La existencia de los vestigios de la adecuación y primera ocupación del solar, correspondientes a la época colonial, se demostró a través del análisis de las caracte-

\footnotetext{
${ }^{26}$ Marta Cecilia González, Estudio histórico de la Casa de los Comuneros II, ms., 1998.
} 
risticas de la secuencia estratigráfica, la traba de los cimientos y muros y los materiales culturales encontrados en los estratos más profundos.

Los criterios utilizados para identificar estas estructuras más antiguas fueron: 1) las características de los cimientos, los cuales poseen diferencias notorias en los materiales que los componen, así como su correlación con los muros con los que presenta o no trabas, ${ }^{27}$ 2) las características de los muros que se erigen sobre estas bases y, 3) el material cultural asociado.

Los cimientos más antiguos, contrario a lo esperado, se encontraron a lo largo de todo el predio, en efecto, no muestran una evolución de la casa en sentido oriente-occidente, como originalmente se planteó. El segundo paso del análisis, el de los muros, señala que todos corresponden a la misma época, pues se trata de muros en tapia pisada, hoy alterados casi en su totalidad por las modificaciones hechas posteriormente a la casa.

Otra característica consistente en todos los muros y cimientos detectados como antiguos, es que carecen de traba con aquellos que los cortan o separan de las casas vecinas actuales, es decir, en los linderos con las edificaciones contiguas tanto en el costado izquierdo como en el derecho. Esto es muy importante para entender la evolución del inmueble e indica que la actual casa fue recortada en algún momento; muy posiblemente el predio estuvo conectado o hizo parte de uno o los dos predios aledaños. Se puede concluir que el predio acusaba una orientación norte-sur.

\section{Material arqueológico}

En los espacios cercanos a la calle de Santa Clara (carrera octava) no se hallaron materiales culturales asociados a esta primera ocupación. En otros sondeos, hacia el interior, los materiales culturales encontrados en el estrato más antiguo (espacios 110 y 115), corresponden en gran parte a materiales cerámicos indígenas o con fuerte tradición indígena. Además se excavó loza vidriada común de tradición europea, y otros materiales de uso doméstico para la elaboración de la comida (almacenar, cocinar, servir). Estos objetos, de acuerdo a sus características formales y funcionales, así como

27 Esto se analiza más extensamente en Monika Therrien, "Sociedad y cultura material de la Nueva Granada ¿Preferencias o referencias? Aportes de la Arqueología Histórica en Colombia", Revista Colombiana de Antropología, vol. XXXTC1, Bogotá, Instituto Colombiano de Antropología, 1997, pp. 5-51. 
por los patrones demográficos y de comportamiento cultural estudiados para Bogotá, señalan que este primer nivel de adecuación del espacio pudo haberse desarrollado entre 1550 y 1650.

Con respecto a las características de los materiales y a la presencia de objetos indígenas, parecen corresponder a una práctica común de la época. Según Vargas Lesmes, de esa inmensa mayoría de indígenas (en relación con el número de españoles) que vivían alrededor de Bogotá, muchos se incorporaron a la ciudad como sirvientes. A través de documentos se constata que los españoles, con el ánimo de mantenerlos disponibles, permitieron que ellos construyeran sus bohíos en los solares o patios traseros. Aún más, por desinterés de los españoles (¿intencional o inconsciente?), los indígenas realizaron, al amparo de las tapias que encerraban los solares de las casas de los españoles, sus bailes y celebraciones tradicionales, los cuales perduraron hasta el siglo XVII. ${ }^{28}$

Entre los servicios que debían desempeñar estos indígenas estaban el de conseguir agua, asear y mantener la casa, labores de cocina, adecuación de la leña y carbón para mantener el fuego, cuidar los animales, las labores de huerta, aseo y reparación de ropa, crianza de niños, mandados y recados, amasar y hacer jamones. ${ }^{29}$ Lo que quiere decir que se debía contar con un buen número de sirvientes para tantos oficios.

Los materiales arqueológicos que delatan la presencia de estos indígenas en el predio, presentan características que los hace semejantes a las copas ricamente decoradas con diseños geométricos y por fuera, con la aplicación de culebras. Estas las usaron los indígenas durante el período prehispánico y, frecuentemente, se encuentran como parte del ajuar para sus muertos. Se podría afirmar que las copas se siguieron usando en el contexto de las celebraciones y rituales mencionados.

Asociados a estos objetos tambien se encontraron fragmentos de platos de forma indiscutiblemente española, pero cuya decoración es idéntica a la de las copas indígenas. Dicho comportamiento indica no sólo la presencia de los estilos hispanos integrados al material nativo, sino su apropiación y adaptación a los gustos y hábitos indígenas. Indicios de esta práctica ya se

\footnotetext{
${ }^{28}$ Julián Vargas Lesmes, La sociedad de Santafé Colonial, pp. 53-54. ${ }^{29}$

Ibid, p. 146.
} 
habían detectado en otro contexto donde, como parte del ajuar de una tumba indígena excavada al sur de Bogotá, ${ }^{30}$ se halló un collar de cuentas de vidrio españolas, las cuales habían sido recubiertas con pinturas y diseños de los aborígenes. Estas expresiones parecen mostrar, más que una imposición y un sometimiento, una negociación en las relaciones de dominio.

\section{Síntesis}

A partir de las distintas evidencias encontradas, y en contraste con la documentación histórica que existe para la época y para la casa específicamente, se plantea que el predio donde se encuentra actualmente la "Casa de los Comuneros II", no fue un predio independiente durante la época colonial. Por el contrario, de acuerdo con la ausencia de trabas evidentes en los linderos actuales al norte y sur, esta casa hizo parte de un inmueble más grande, con uno o más de los predios aledaños. Por las características de los materiales encontrados, se añade además, que la Casa de los Comuneros II, en su ocupación más temprana correspondiera a una huerta o lugar de la servidumbre, dadas las características indígenas del material encontrado en los estratos más profundos del sitio.

Además de la arqueología, otra de las herramientas que se considera puede dar algunas luces para la comprobación de este planteamiento, es la del análisis documental y social del desarrollo urbanístico específico del área de interés del proyecto.

\section{La lectura documental: retórica de la edad o reafirmación de una identidad}

Con referencia a la inquietud sobre el eje de evolución del predio, el período de adecuación de la casa y las características del sitio en su primera ocupación, es necesario contrastar las evidencias arqueológicas con la interpretación del testamento escrito por el genealogista colonial don Juan Flórez de Ocáriz, quién habitó durante muchos años la casa de la esquina suroccidental de la Plaza Mayor (colindante hoy con la "Casa de los Comuneros II"). Esta la adquirió así:

30 Arturo Cifuentes y Leonardo Moreno: Proyecto de rescate arqueológico de la avenida Villavicencio (Barrio Candelaria La Nueva - Bogotá). Informe Instituto Colombiano de Antropología-ICAN (inédito), 1987. 
"Por concurso de acreedores se trajeron en venta y pregón las casas y tiendas que fueron de Pedro Díaz Ochoa y Ana de Mendoza, su mujer, que hacen esquina en una de las de la plaza con la del Real acuerdo y Audiencia por una parte y por la otra con la cárcel de esta ciudad, calles en medios de las que bajan de la Plaza a los conventos de Santa Clara y de la Concepción,... con pacto del bachiller don Francisco de Mendoza, presbítero, de quedarse con las cinco tiendas (que son las cuatro en hilera y la otra sola a la vuelta de la calle junto a la portada v el zaguán)...". 31

Es indispensable hacer énfasis aquí sobre las circunstancias en que Flórez de Ocáriz escribe su testamento, pues en 1692, año en que lo redacta, tiene 80 años, edad notable para la época. El análisis del documento es bastante difícil, bien sea por la edad o el estilo de redacción reiterativo -propio de la época-, y por esto se considera necesario detenerse para explicar esta interpretación de los resultados.

En primer lugar, al analizar todo el texto del testamento, se observa que hace alusión a las casas de acuerdo a diferentes ítem, en este orden: 1) posesión de propiedades, 2) gastos incurridos en mejoras y/o construcciones, y 3) usufructo y/o función de las mismas. Al dividir de esta forma los términos de su testamento, Flórez hace alusión reiterada de las mismas casas y tiendas que posee. Es así como, en el ítem sobre la posesión de bienes (además de la ya citada arriba), se refiere a:

"...la casa alta con sobrado y oficinas y las cuatro tiendas que tiene debajo, que lo uno y lo otro está inmediato y contiguo a las casas principales en que vivo, que al presente habita Doña Ana Palacín, viuda de Valentín de Heredia, que linda por el otro lado con otra casa mía, que ambas edifiqué, y la más apartada con casa de Doña Inés de Saavedra, viuda de Jacinto de Espinosa y Mendoza, todo en la calle y primera cuadra que baja de la Plaza Mayor al convento de la Concep-ción...".

\footnotetext{
${ }^{31}$ Enrique Ortega Ricaurte, "Testamento de don Juan Flórez de Ocáriz", Boletín de Historia y Antigüedades, Vol. XV, p. 486, (el subrayado es mío).

${ }^{32}$ Ibid, p. 482, (el subrayado es mío).
} 
Con respecto al ítem de mejoras y/o construcción vuelve a referirse tanto a su propia casa (casas como la denomina en este caso) y a las otras dos. Sobre la suya señala que:

"Las dichas casas estaban muy deterioradas y así en repartirlas y mejorarlas he gastado más de lo que puedo apuntar por que se calzaron los cimientos interiores, se pusieron vigas, se alzaron tapias caídas y fabriqué un cuarto en frente de la calle de la portada para cocina, amasadero y despensa con corredores a ambos lados y escalera al corral, letrina y entablado a ella, que subió de mil cien pesos de más de lo obrado en gallinero, caballeriza con pesebreras, puertas, ventanas,...; más otras he gastado en hacer tabiques, alcobas, dorados, pinturas, llaves, cerraduras y otras varias cosas precisas y el portón de la casa, puerta que no había tenido..."33

Y, para reforzar estructuralmente su casa, debido al mal estado en que se encontraba, construye las otras dos:

"Por la mayor seguridad de las casas [la suya] dándoles estribo y arrimo por la parte de abajo, edifiqué dos casas en la que había sido parte de la huerta, cada una con cuatro tiendas y segundos altos de vivienda con cerca alta que impidiese ver y registrar las oficinas". ${ }^{34}$

Por último, en lo que se refiere al usufructo de los inmuebles, contaba Flórez de Ocáriz con las dos casas y las cuatro tiendas de cada una de ellas, además de "...la última tienda que cae debajo de la dicha casa la hice yo de un aposento de ella que era amasadero antiguo y es mía, y la tengo alquilada y no es de las otras del censo, y esto es así mismo mejora de las dichas casas". Por lo que se describió inicialmente, se sabe que las tiendas localizadas en el primer piso se destinaron para el usufructo de don Francisco de Mendoza, lo cual, no obstante, no impidió que Flórez lo reiterara nuevamente: "El poseedor de las tiendas que están debajo de la dicha mi casa principal está obligado a tenerlas reparadas de modo que no redunde en perjuicio a dicha casa...". ${ }^{35}$ Sobre las funciones o actividades de su casa, se ha visto que

33 Ibid, p. 488

34 Ibid, p. 488, (el subrayado es mío).

35 ibid, pág. 489. 
menciona el nuevo amasadera y anexos, la portada y el zaguán sobre la calle de Santa Clara, las caballerizas, gallineros, letrinas y demás usos.

\section{El solar de la esquina de la calle de Santa Clara y del Divorcio}

Como resultado de la lectura del testamento y en conjunto con las características estructurales evidentes en la "Casa de los Comuneros", cimientos, muros y materiales arqueológicos hallados en las excavaciones, se propone que al menos en esta manzana, la dirección en que se desarrolló la subdivisión de los solares se efectuó teniendo en cuenta la importancia de la calle del Divorcio (la cual conducía a dos de los conventos), sobre la cual se construyeron las casas que Flórez tenía alquiladas a las dos viudas.

Más aún, podrían indicarse las estructuras en las cuales se desarrollaron algunas actividades que describe Flórez en su documento. En lo que se refiere a las mejoras a su casa, hace alusión a que el amasadera, cocina y despensa, desembocan en una escalera, lo cual permite suponer que éstos los construyó en el segundo piso, sobre la calle de Santa Clara (la de la portada). Añade que de estos nuevos espacios se baja por una escalera al corral, las letrinas y el entablado. Estas escaleras corresponderían a las huellas estructurales aún existentes en el espacio 104, identificadas por los arquitectos (el espacio no se pudo excavar por estar ocupado actualmente por un almacén).

De otra parte, la mención que hace Flórez sobre la construcción de dos casas hacia el occidente, para reforzar estructuralmente su propia casa, parece corresponder con los cimientos 5 y 6, dadas las características especiales del uso de mortero de cal y arena a la vista. La profundidad de estas bases también coincide con lo que él expresa como que el terreno está "cuesta abajo". Todo esto se reforzaría con la cronología de los materiales culturales encontrados. Como se señaló antes, corresponden al período entre 1550-1650 aproximadamente, es decir, que las mejoras efectuadas en su casa y las otras construcciones ocurren a partir de la fecha más reciente (1650, según los principios estratigráficos definidos). Según los análisis aquí expuestos se propone la siguiente evolución del solar, el cual incluye el predio de la "Casa de los Comuneros", englobado dentro del mismo. 

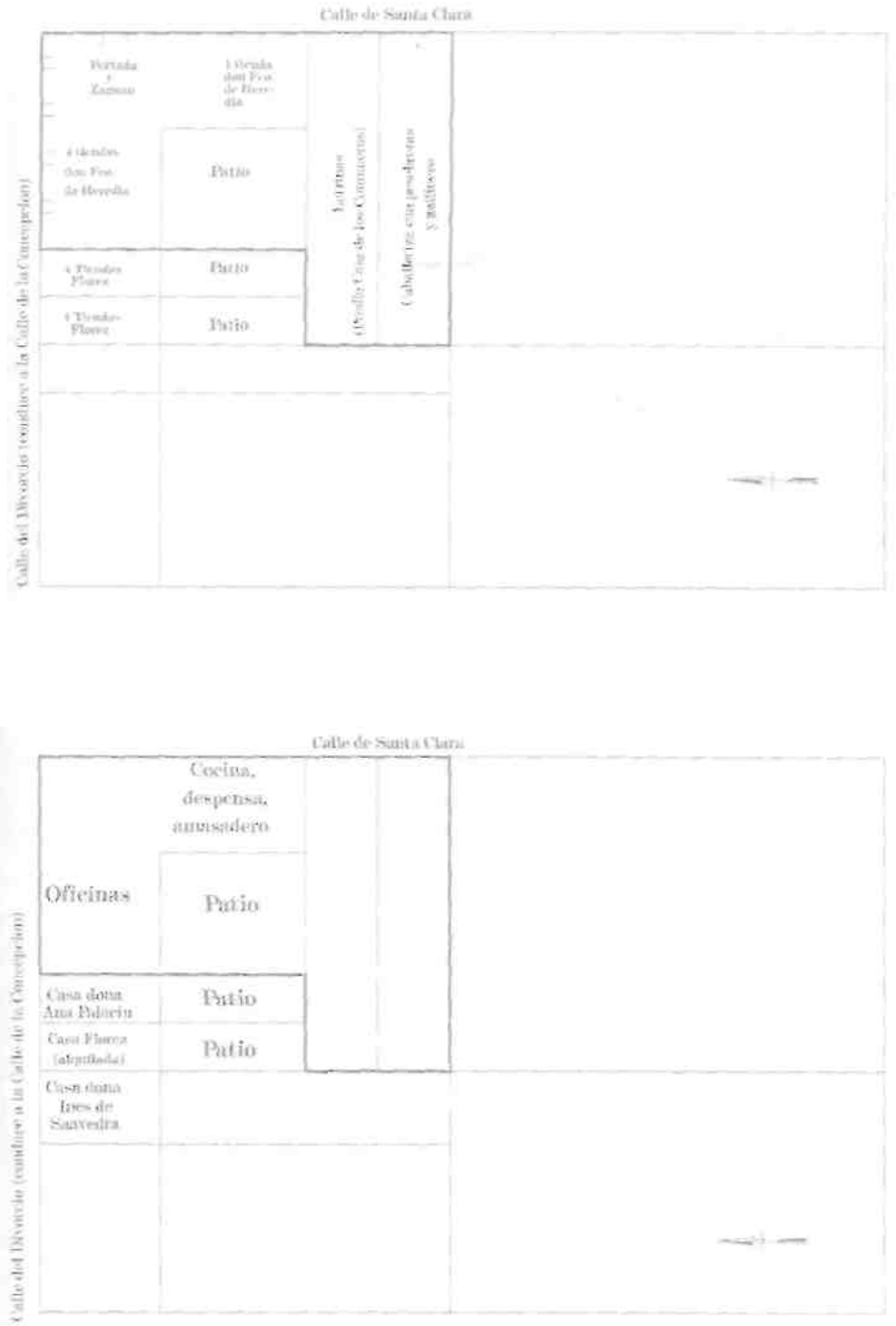


\section{SIGLO XIX}

\section{Generalidades}

Al comenzar el siglo, en 1807, Bogotá cuenta con una población de casi 23.000 habitantes y para 1893 se calcularon aprox.135.000. ${ }^{36}$ Sin embargo, una de las características más constantes a lo largo del siglo, es que el crecimiento demográfico se siguió desarrollando dentro de los mismos límites urbanos que se habían establecido en la época colonial. Prácticamente la mayor parte de la población se concentró en las parroquias de las Nieves y de la Catedral. La concentración del barrio del Palacio era menor que las anteriores.

Las relaciones entre indígenas y españoles, a pesar de los esfuerzos durante la Colonia de establecer las diferencias étnicas y sociales, muestran como resultado una prevalencia del mestizaje en distintos ámbitos y algunos hábitos y costumbres, así como la consolidación de otros nuevos. Incluso, aunque con ciertos avatares y a regañadientes, el único noble de Bogotá, el marqués de San Jorge, renunció a su título real para acoger una nueva personalidad patriota de "igualdad".

Gradualmente, la densidad demográfica y las características de la población mestiza en consolidación, los nuevos aires políticos y, con ellos, las nuevas aspiraciones sociales y económicas, hicieron que poco a poco la ciudad abandonara su aspecto colonial y adquiriera otra semblanza y otros hábitos.

\section{El barrio del Palacio}

Para analizar y entender las modificaciones efectuadas en la "Casa de los Comuneros II", se considera necesario un recuento de los cambios del contexto urbano en el cual se circunscribe el predio. Además, ésto permite conocer las actividades, nuevas o tradicionales, que se desarrollaron en la ciudad durante esta época y las relaciones sociales y culturales que se establecieron a través de ellas.

Uno de los aspectos mas sobresalientes en Bogotá, durante el siglo XIX, es el cambio en la nomenclatura de sus calles. En pocas décadas, la ciudad vio

${ }^{36}$ José María Cordovez Moure, Reminiscencias de Santafé y Bogotá, p. 1543, apéndice. 
como pasaron de ser un referente social y religioso, a conmemorar los hechos de la Independencia, para finalizar con el sistema numérico que rige hasta hoy. Este último sistema también generó incertidumbre respecto a cuál debía ser el punto 0 de iniciación. Aunque inicialmente se tomó como eje la Plaza Mayor, luego se decidió por la manzana que en aquel entonces quedaba más alejada de la ciudad, en los cerros surorientales.

El predio de la "Casa de los Comuneros II", estuvo localizada en la calle que sucesivamente recibió los siguientes nombres: calle de Santa Clara, carrera del Ecuador (con carrera del Perú al costado norte), carrera la. al occidente (en la cuadra 10) y, finalmente, hoy carrera octava (con calle décima).

En comparación con el ambiente urbanístico un tanto desolado que presentaba el sector de la "Casa de los Comuneros II" durante la Colonia, a partir de la Independencia se convierte en una zona más activa. De un lado, desde finales del siglo XVIII funcionaba la casa de la Expedición Botánica sobre la antigua calle de la Carrera o carrera del Sur, y en 1803 se inaugura el Observatorio, sobre la calle de Santa Clara o carrera del Ecuador. Con ellos, se marca la entrada de la Ilustración, no sólo al Nuevo Reino, sino a este sector en especial.

Contiguo al Batallón Auxiliar, donde funcionó inicialmente el Colegio San Nicolás de Bari ubicado en la antigua calle de la Giralda o carrera del Ecuador, se establecieron, además, la dirección de rentas y las cámaras legislativas. En la manzana siguiente, la Sociedad de Educación Primaria construyó junto al Observatorio la escuela Santa Clara, en 1843, según Holton esta era para varones y contaba con una buena fachada. ${ }^{37}$ La escuela pasó a ser después el Teatro Nuevo de Variedades ${ }^{38}$ y sobre él se inició el proyecto de construcción del Teatro Municipal en 1887, el cual se culmina en $1890 .{ }^{39}$ En 1900, el Observatorio cedió un pedazo de terreno para construir los camerinos y dar así acceso a los actores por la carrera octava. ${ }^{40}$

Otro cambio de gran notoriedad fue el inicio de la construcción de los portales en el costado occidental de la Plaza Mayor en 1846, conocidos como

\footnotetext{
${ }^{37}$ Isaac Holton, La Nueva Granada. Veinte meses en los Andes, Bogotá, Banco de la República, 1981 [1857], p. 208.

${ }^{38}$ Marina Lamus, Teatro en Colombia: 1831-1886, Bogotá, Editorial Ariel, 1998, p. 115.

39 Pedro M. Ibáñez, Crónicas de Bogotá, 1989, p. 605.

${ }^{40}$ Marina Lamus, Teatro en Colombia, p. 118.
} 
Las Galerías, que perduraron hasta 1900 cuando fueron devorados por un incendio. También en 1846, el General Mosquera decide dar un nuevo uso y aspecto a la vieja casa de la Real Audiencia, para ésto encomienda a Thomas Reed el diseño del futuro Capitolio, cuya construcción se prolonga por ochenta años. Aún en 1906 se observa, frente a la "Casa de los Comuneros II", una profunda grieta en los cimientos, ocasionada tanto por la presencia de los cimientos de la antigua casa que se dejaron in-situ, como por la mala calidad del suelo en esta manzana. ${ }^{41}$

Como mejoras para el sector, se construyó en 1872 en la cuadra o calle 10, entre las plazas de Bolívar y del Mercado, la primera alcantarilla o albañal que se vio en Bogotá y se cubrió el pavimento de la primera cuadra con adoquines. $^{42}$

No sólo faltaron los agentes naturales como los terremotos para causar desgracias, sino también estaban aquellos ocasionados por el descuido humano. Cordovez Moure relata que en 1855, en el primer piso de la vivienda de Domingo Hernández, rico comerciante que ocupaba las casas 178-184 sobre la carrera del Ecuador y contiguas al Teatro Municipal, se produjo la violenta explosión de un barril de pólvora. Esta destruyó su casa, al igual que la del costado norte y la puerta de Santa Clara que da sobre esta calle. Los escombros volaron por los aires y llegaron hasta la Plaza Mayor, en ese día que era viernes de mercado. Se calculó que además de los muertos, los daños causados por esta explosión ascendieron a 100.000 pesos, una fortuna para la época. ${ }^{43}$

Aunque el proceso de activación del sector fue lento, para mediados del siglo XIX es evidente que la cuadra en cuestión tomó más vida, lo cual coincide con el auge económico de la ciudad y de algunos de sus habitantes, entre ellos el rico comerciante Arrubla, quien financia y emprende varias de las obras de mayor envergadura. Paralelamente a este proceso, el aumento de la población, obligó a la subdivisión de las viviendas, ya que en términos urbanos dicha densidad no se tradujo en una expansión de la ciudad a los campos contiguos. $^{44}$

\footnotetext{
Alfredo Ortega Díaz, Arquitectura de Bogotá, p. 54.

${ }^{42}$ Pedro M. Ibáñez, Crónicas de Bogotá, p. 571.

43 José M. Cordovez Moure, Reminiscencias de Santafé y Bogotá, pp. 810-814.

${ }^{44}$ Fundación Misión Colombia, Historia de Bogotá, t. 2, p. 10.
} 
Incluso podría decirse que la importancia de las calles se invierte, por cuanto en la antigua calle de Santa Clara se condensan en el siglo XIX actividades como la ciencia, la educación, la cultura e incluso de la guerra. Por el contrario, luego de la expulsión de las órdenes religiosas del país, por la antigua calle del Divorcio sólo se llega al mercado cubierto, construido también por Arrubla, en lo que fueron las huertas del convento de la Concepción. Cambia el eje de las relaciones en el área, así como en el predio de la Casa de los Comuneros.

\section{La "Casa de los Comuneros" y el cambio de eje}

Como resultado de las evidencias, recolectadas arqueológicamente y de las crónicas de escritores locales así como de los viajeros, podría plantearse que es a partir de la mitad del siglo XIX cuando la "Casa de los Comuneros II" invierte su sentido de uso de norte-sur al de oriente-occidente. Así se consolida como un espacio independiente, dentro del cual poco a poco se efectúan algunas de las mejoras por la cuales adquiere el estilo conocido como republicano, con fachada, distribución de los espacios, sus papeles de colgadura en las paredes y la yesería en los cielos rasos correspondientes.

\section{La secuencia estratigráfíca}

Es notorio el cambio que sufre el predio de la "Casa de los Comuneros II" durante este siglo. Podría decirse que es el de una intervención tan profunda que casi logra borrar las huellas pasadas.

Las características de los cimientos, los muros y los materiales culturales pertenecientes a éste período, indican que la intervención implicó el total alinderamiento de la casa de la esquina, para convertirla en una casa independiente, conocida hoy como "Casa de los Comuneros II".

Como casa independiente, ahora sí es posible analizar su evolución y uso en sentido oriente-occidente. Es así como se observa que el muro del cimiento 7 se demolió para dar paso a un zaguán e instalar, a cada lado, una tienda con trastienda. Esto condujo a reforzar los muros de tapia pisada existentes (el 2 y el 3): el muro 2 se abrió en dos partes para dar acceso al nuevo zaguán y para que de la tienda se pudiera acceder a la trastienda. Igualmente en el muro 3 se abrió otra entrada, posiblemente a un depósito. 
El muro de la fachada fue remodelado totalmente para dar cabida al nuevo estilo "republicano". La característica que marca la remodelación de la casa es el refuerzo de los muros de tapia con ladrillos cocidos, cuya calidad deja mucho que desear. Sólo donde existía la tapia pisada se utilizó este material, el resto de las adecuaciones modernas de la casa se hicieron con adobes (muros 13 y 14).

De otra parte, la incorporación en la construcción de dos tiendas, a lado y lado del zaguán, con sus respectivas trastiendas condujo a desplazar la escalera colonial. Para ello se elaboró una nueva, cuyo estilo republicano bien definido, delata la época de su construcción; los cimientos también permiten evidenciar este cambio, que a su vez, comprometió la columna y el arco coloniales presentes en el corredor, restándole mérito al estilo.

En las radicales transformaciones que se ocasionaron en esta parte del antiguo solar de la casa de Flórez, aún queda por entender por qué no se respetó el lindero original del costado sur del predio de Flórez de Ocáriz, el cual no es recto sino que presenta salidas y entradas. Es posible que ésto se deba a la adición de un segundo piso, sobre la estructura existente con anterioridad, lo cual llevó a construir muros internos para soportar la carga.

\section{Material arqueológico}

A diferencia del período anterior, y tal vez debido a las modificaciones profundas que sufrió la casa, la cantidad de material cultural fue mucho mayor. En comparación con las características de los materiales de la Colonia, la presencia de objetos indígenas desaparece casi por completo (su tradición se mantiene especialmente para las vasijas culinarias), pero lo que sí se evidencia es el material mestizo relacionado con la tradición indígena. Se observa una continuidad en la forma de los platos hallados en el estrato anterior, pero aquí su decoración delata un cambio, en ellos no se trata de imitar los diseños europeos, y aunque ciertos colores y trazos guardan alguna relación con la decoración indígena, los motivos son muy diferentes. De otro lado, aumenta el volumen de material de cerámica vidriada (verde, naranja, amarilla), quizá por el establecimiento de fábricas de loza en la ciudad, las cuales se desenvolvieron con relativo éxito.

La presencia de loza inglesa es la que permite datar con mayor aproximación el período en el cual se efectúan los grandes cambios en el predio. 
Sobre la industria locera inglesa se ha llegado a saber con precisión la fecha en que se produjo y dejó de elaborarse un determinado diseño o vajilla. La evidencia de este material dentro de un estrato, indica que sólo pudo incorporarse en el relleno durante o después de ese lapso de tiempo. En la Casa de los Comuneros se encontraron varios fragmentos diagnósticos, en los estratos que corresponden al alinderamiento y construcción del actual inmueble, cuya cronología los sitúa a mediados del siglo pasado, 1850 aproximadamente.

Dicha fecha también coincide con la época de mayor producción y exportación de artículos en el mundo, no sólo de vajillas. Las bondades de la industrialización eran patentes en los inmensos catálogos que ofrecían toda clase de productos, desde tinas con calentador a vapor incorporado, carpas y hamacas hasta lupas, armas, cubiertos y otra infinidad de objetos.

No obstante contar con el dato provisto por la loza inglesa, es importante también considerar las condiciones económicas del país y de la ciudad, para establecer con mayor precisión la época en que se transformó el predio en una casa independiente. Por lo que se deduce del análisis económico interno y externo del siglo XIX, especialmente de la segunda mitad, ${ }^{45}$ las condiciones de adquisición de bienes materiales y comodidades, en especial por parte de las clases medias, se hizo posible a partir de 1860 . El bienestar económico de la época puede tomarse como otro indicativo temporal para las modificaciones descritas.

Aunque la explosión de la producción industrial puso al alcance de las manos de muchos estos objetos extranjeros, como por ejemplo la loza inglesa, para los bogotanos acceder a ellos no fue tan fácil. No existía una exportación directa al país, sino que aquellos materiales se conseguían generalmente o bien en alguna isla del Caribe o a través de Estados Unidos. Pero tal vez lo más difícil fue lograr que estos frágiles objetos llegaran indemnes hasta Bogotá, en el lomo de una mula que los traía desde Honda. Tal y como narran algunos viajeros de la época, era más económico contar con una vajilla de plata. ${ }^{46}$

\footnotetext{
45 José Antonio Ocampo, Colombia y la economía mundial, 1830-1910, Bogotá, Tercer Mundo Editores, 1997.

46 John P. Hamilton, Viajes por el interior de las provincias de Colombia, Bogotá, Banco de la República, 1993 \{1827\}, p. 136.
} 
Aunque el aspecto cronológico de los materiales culturales sea un indicador valioso, lo es también la interpretación de sus características y uso. Sobre lo que se consumió en estas vajillas, se tienen varias descripciones, que revisten importancia para dar cuenta de los cambios en los hábitos y costumbres de los individuos y las razones detrás de ellos. Del naturalista francés Boussingault, fruto de su visita al agitado nuevo país entre 1812-13, cuando recién se había dado inicio al proceso de Independencia, se tienen algunas descripciones de las comidas que tomó durante su estancia. Según él en la casa de la gente distinguida se servía la "olla podrida", un plato especial que era una herencia de los españoles y consistía de "...un pedazo de buey hervido en medio de papas, manzanas, duraznos verdes sin semilla, garbanzos, arroz, repollo y tocino... A la olla sucedió un plato de repollo ornamentado de salchichas y [para tomar] más caldo". ${ }^{47}$ Igualmente, como lo señala Aída Martínez, la culinaria ha sido un foco de resistencia pero a la vez de identificación de los grupos sociales y culturales y, así como permanecía la herencia peninsular, entre las clases bajas "...los alimentos no eran diferentes... Los artesanos, no muy numerosos y los campesinos, se alimentaban especialmente de ajiaco, que es una mezcla de carne de res o de oveja, cortada finamente y cocida con papas y sazonada con ajo y cebollas...". 48

Holton, otro viajero que llegó varias décadas después hace mención de la olla podrida, pero solo para puntualizar que nunca la pudo probar. A pesar de ser un plato que servían con frecuencia en Bogotá para agasajar algún invitado, a él no se la ofrecieron jamás. Sin embargo, manifestaba su alegría por ésto, pues temía que le desagradara su sabor. Posiblemente este tradicional plato ya estaba en desuso cuando realizó su visita y estaba imponiéndose el plato de los artesanos, el mestizo ajiaco, que se conserva hasta hoy.

Con los nuevos aires de la república venidos de los nuevos ejes de poder, europeos (ingleses y franceses) y luego norteamericanos y con ellos sus hábitos y costumbres, preferidos por aquellos miembros de la élite que los legitimaba, era inevitable que llegaran los exóticos implementos de mesa y se diera el paulatino cambio en la alimentación. Como lo narra Vergara y

47 Aída Martínez Carreño, Mesa y cocina en el siglo XIX, Bogotá, Fondo Cultural Cafetero, 1985, p. 28.

48 Bousingault, en Aída Martínez, Mesa y cocina, p. 29. 
Vergara, ${ }^{49}$ los productos que vencieron la tradición del consumo del chocolate fueron el café y el té, introducidos al país en ese orden. ¿Pero que más refinamiento se podía demostrar que tomar el té en la vajilla inglesa decorada con motivos chinos? Las herencias hispanas como la olla podrida y las nativas, como el chocolate, daban paso a un nuevo ciclo social que dejaba atrás ese pasado ¿Sería posible realmente?

En cuanto a los análisis de macrorrestos de fauna y plantas, se tienen datos que permiten saber lo que consumieron los habitantes de la Casa de los Comuneros. Aunque por ahora sólo se conocen preliminarmente los resultados de la flotación de suelos para la identificación de plantas, se evidenciaron semillas secas de varios frutos y vegetales, de los cuales vale la pena explorar el por qué de su estado, ya que no es común encontrarlos secos. Por ahora, se han identificado tres semillas: cebada, mora y una passiflora, posiblemente de granadilla. ${ }^{30}$ Esta información es especialmente interesante por cuanto estos tres productos poco los mencionan los viajeros, posiblemente porque se trate de los más comunes, bien por su presencia en la huerta (las moras) o por su consumo frecuente en sopas (la cebada).

De la fauna se encontraron restos de cerdo, cordero y res, y posiblemente otro artyodáctilo (el hueso parece de venado). ${ }^{51}$ La característica más interesante que se señala en el análisis de los huesos, es la edad jóven de las especies. Al parecer, los consumidores favorecían las carnes tiernas y por tanto, más suaves. Con repecto al venado, el viajero Hamilton narra su experiencia el día Viernes Santo, durante su visita a Bogotá, en el que se reunieron un grupo de personas para la cacería de venado,

"...entre escabrosos precipicios...propio para romperse la crisma... El ciervo cazado hoy... [era] un hermoso animal de cuernos ramificados, pero no tan grande como nuestro venado rojo y de color algo más obscuro... Su Excelencia el Vicepresidente, conocedor de mi afición hacia los animales, tuvo la bondad de enviarme un ciervo domesticado." 52

\footnotetext{
49 José María Vergara y Vergara. "Las tres tazas". Cuadros de Costumbres. Cali, Carvajal y Cía., 1969 [c. 1870].

${ }^{50}$ Fernando Montejo y Sneider Rojas, Fundación Erigaie, comunicación personal.

${ }^{51}$ Elizabeth Ramos, Universidad de los Andes, comunicación personal.

52 John P. Hamilton, Viajes por el interior de las provincias de Colombia, p. 114.
} 


\section{El análisis documental}

$\mathrm{Al}$ contrario de lo recolectado arqueológicamente, el registro notarial recopilado entre los años de 1795 y $1826,{ }^{53}$ no ofrece indicios sobre el alinderamiento y cambio en el eje evolutivo de la "Casa de los Comuneros" durante este período. Una reconstrucción del desarrollo predial muestra, por el contrario, que se mantiene estable la globalización del predio de la casa con la de la esquina.

Entre 1826 y 1860 no existen registros notariales. A partir de 1860, los documentos recopilados presentan cierta confusión ya que reiteradamente se hace mención en ellos de elementos de identificación que no corresponden a la manzana del proyecto. Estos son: 1) barrio de las Nieves, conformado por las cuadras ubicadas al norte del río San Francisco (hoy Avenida Jiménez) y no está relacionado con el barrio del Palacio o Catedral, 2) o a espaldas o calle enfrente del Hospicio, el cual según los planos estuvo ubicado entre las calles 18 y 19 y, 3) carrera de Venezuela, mientras que la del predio correspondió a la carrera del Ecuador.

A continuación se presenta un esquema predial de la manzana, entre 1795 y 1826:

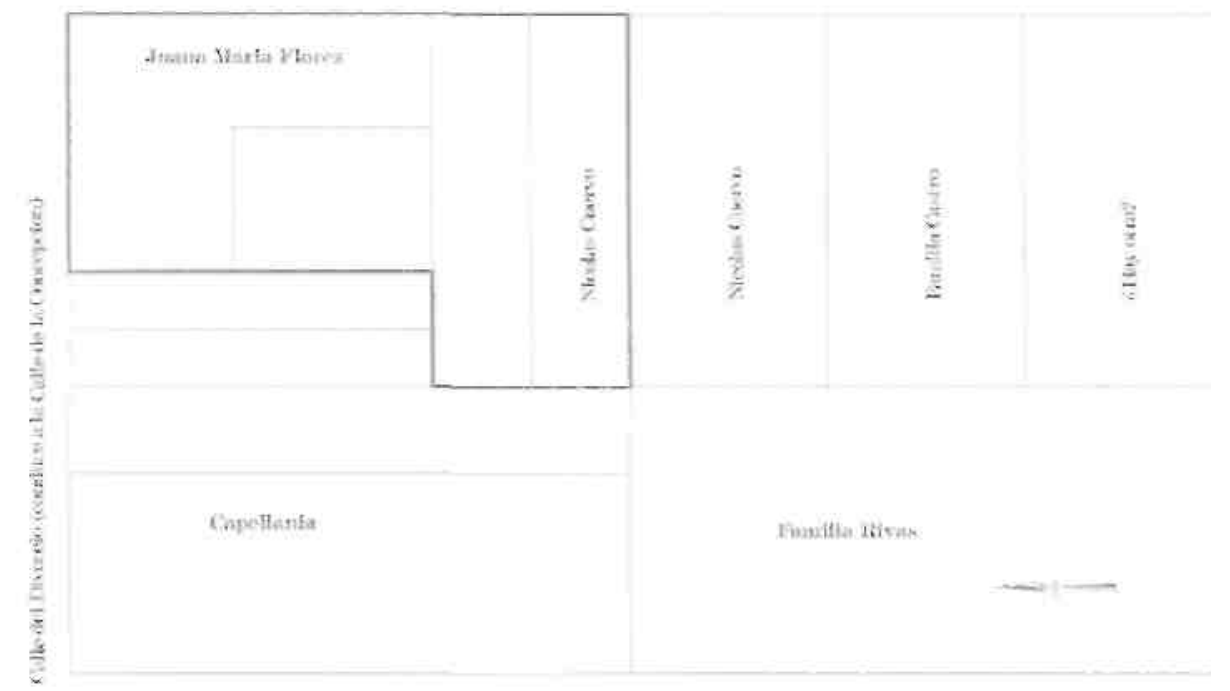

Figura 5. Distribución de los predios entre 1795 y 1826.

Calle de Samo Clara

53 María Cecilia González, Estudio histórico de la "Casa de los Comuneros II", ms. 
A pesar de no contar con el registro notarial completo, se encontró una descripción bastante aproximada de lo que sucedió en la "Casa de los Comuneros II". En ella, que recoge la moda del momento, el costumbrista Ricardo Silva se refiere de manera jocosa a la remodelación hecha en una casa de Bogotá, en 1860 aproximadamente, que no deja de ser muy realista para el caso de la Casa:

"Vea usted lo que yo haría, agregó: quitar el balcón feo y enorme de la calle, abrir los umbralados a la misma altura y a la misma distancia; hacer nuevo el alar sobre canecitos de moda; poner cinco balconcitos de balaustres dorados; abrir, haciéndolos más altos y a igual distancia, los umbralados de las tiendas; quitar el zaguán de donde está y hacerlo en el centro, más estrecho y bonito; ponerle portones nuevos, enchapados de madera y cielo raso sobre una cornisa elegante y vistosa. Esto en cuanto a la calle: ahora, en cuanto a lo de adentro, la obra será más sencilla: levantar los entejados de estos corredores, para lo cual solo habría que cambiar estas columnas viejas y rajadas por otras más altas, ochavadas y con sus capiteles y pedestales de buen gusto y montar sobre estas el penduleado sin tocar las cumbreras; levantar y colocar a igual distancia todos los umbralados de la parte alta; hacer todos los cielos rasos, empezando por el de la sala, que es de lienzo y está manchado y soplado; ponerle a todas las piezas cornisas y florones vistosos y elegantes... empapelar y pintar toda la casa." $^{54}$

Otros ejemplos de vivienda en el siglo XIX:

Charles S. Cochrane, ciudadano inglés que permaneció en Colombia durante los años de 1823 y 1824:

"Los almacenes (tiendas) están situados a derecha e izquierda de la entrada principal de las casas; para este propósito, el primer piso de todas ellas es sacrificado. Por regla general, la familia habita las habitaciones del segundo piso, sobre el lado que da hacia la calle. Alrededor del jardín o patio, están ubicadas las habitaciones de recepción (sala) y frente a la entrada de la casa las habitaciones de la servidum-

\footnotetext{
54 Ricardo Silva, "El remiendito", Cuadros de Costumbres, Cali, Carvajal y Cía., 1969, p. 162. [el860].
} 
bre, los establos, la lavandería, etc.. Todos los almacenes con pocas excepciones, son sólamente tiendas de abarrotes." ${ }^{55}$

"Las casas están construidas con ladrillos secados al aire, cubiertos de tejas blanqueadas, las ventanas de vidrio son raras, lo mismo que los techos de yeso. Las puertas son de varios tamaños y las paredes y escaleras están pintadas con marcos, tejidos de flores y paisajes" 56

"En toda la ciudad no existe ninguna alcantarilla, no obstante que el penetrante olor invita a su construcción" ${ }^{57}$

Isaac F. Holton, ciudadano de Estados Unidos, visitó Colombia en 1856:

"Las familias viven en el segundo piso de las edificaciones y en el primero, que no tiene ventanas, hay almacenes... La primera y segunda puerta de la izquierda son tiendas, la tercera, medio escondida detrás de dos figuras femeninas, es el portón de una casa; al entrar se pasa por el zaguán al patio y se sube por las escaleras a las habitaciones del segundo piso" ${ }^{58}$

"Vivía en una pieza en el primer piso de una casa alta, y a pesar del frío que hace en Bogotá tenía que dejar la puerta abierta para que entrara luz... Más adentro había una pieza, aún más pequeña sin puerta ni ventanas... ¿ ¿Y dónde está la puerta para entrar al patio? ¡Naturalmente que no hay puerta ni tiene derecho a tenerla...! Entonces ¿qué puede hacer, a dónde puede ir? Porque ni en sueños existe ninguna clase de comodidad moderna, ni siquiera alcantarillado. Fuera de sus dos cuarticos, apenas tiene libertad para ir a las calles, lotes vacíos y a la orilla del río... Generalmente se considera que el piso de abajo es menos saludable que el segundo, y así en cada casa apenas hay una familia que puede gozar del patio. El cuarto de adelante de estas cuevas, excavadas prácticamente en los cimientos de las mejores casas..."

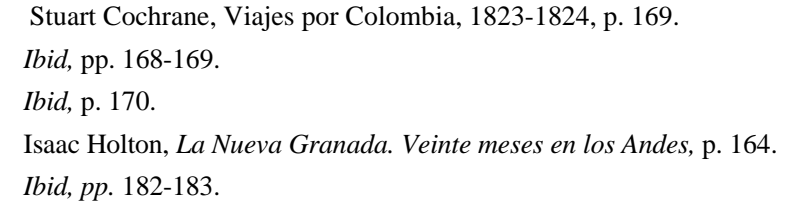




\section{Síntesis}

Aunque se había estimado que el inmueble "Casa de los Comuneros II" tenía un origen colonial, se plantea que hizo parte de la casa más grande, que a partir de 1642 fue propiedad de don Juan Flórez de Ocáriz. Posiblemente en la parte del predio donde se efectuaron las excavaciones, se localizaron el gallinero, letrinas, huertas y caballerizas a las que hace alusión en su testamento. Sin embargo, se propone que después de la segunda mitad del siglo, esta parte del terreno fue alinderado y se dio inicio a la construcción del actual inmueble republicano, para lo cual sus constructores se apoyaron en las estructuras antiguas de algunos muros y construyeron otros nuevos, al norte y sur, con los que dividieron definitivamente el predio.

\section{SIGLO XX}

Por la complejidad de las transformaciones de la ciudad, es imposible abordar el siglo XX de la misma manera que los anteriores. No sólo se dificulta abarcar los rápidos e innumerables cambios en el desarrollo urbano, sino que paradójicamente se cuenta para ello con menor información tanto de la estructura de la casa, así como de escasos materiales culturales de este siglo, en la medida en que las basuras ya son recogidas y no acumuladas en un rincón trasero del predio. Por lo tanto, sólo se hará referencia a las adecuaciones puntuales efectuadas en el inmueble durante el presente siglo y con ello se reflejarán algunas de estas transformaciones ocurridas en el ámbito urbano.

Los diversos usos dados después a la casa, significaron cambios radicales como la inclusión de baños y los desagües que ésto implica. La mayoría de ductos hallados en los sondeos, fueron construidos a comienzos del presente siglo, al igual que la instalación del piso de adoquín por toda la casa y los patios. Indicio de ello es que tuvieran que recurrir a buscar en otros lugares el material para rellenar y elevar el piso de los inmuebles, como en algunos espacios en los que se encontró que los adoquines fueron sentados sobre un estrato de desechos de material ferroso carbonizado, al parecer retal de una fábrica de puntillas.

El adoquín instalado en los pisos no es homogéneo, lo cual hace pensar que para adecuar la casa con la instalación de los ductos de aguas, se levantaron los pisos de la remodelación anterior y se reutilizaron adicionando nuevos, de aproximadamente el mismo tamaño aunque no igual, en remplazo de los fallantes. 
Sólo en un espacio, colindante con la carrera octava, se encontraron los vestigios más modernos de relleno, que se han fechado alrededor de 1980. En su estrato superficial se encontraron tapas de gaseosa con sello de corcho en su interior, los cuales se dejaron de producir por esa época. También se hallaron botones plásticos, cintas de una primera comunión, fragmentos de globos, etc.

Como documento final para el siglo XX se anexa un plano del resultado de una visita descriptiva que hizo la Sra. Aura de García, quien en 1955 cuando llegó del Tolima, se hospedó en la que fue entonces la Pensión Araque. El recorrido corresponde al segundo piso esencialmente.

\section{CONCLUSIONES}

A partir de la interpretación de los resultados de las exploraciones arqueológicas y los documentos escritos, y en el contexto más amplio del proceso de desarrollo urbano e histórico social y cultural, se concluye que durante el período colonial, la presencia de estructuras en el predio conocido como "Casa de los Comuneros II", es consecuencia de la evolución del solar y la casa que perteneció al genealogista don Juan Flórez de Ocáriz, situada en la esquina suroccidental de la manzana. Específicamente, la sucesiva construcción y fraccionamiento interior de los espacios que dan contra la carrera octava, se dio por los cambios que realizó su propietario en esta parte del solar, de acuerdo con sus intereses y necesidades sociales y culturales. Con ellas mejoró y aumentó los espacios requeridos para las actividades propias de un miembro de la élite santafereña colonial: en el área social instaló puertas y ventanas grandes, alcobas, dorados, pinturas y hasta portón; en el área de servicios hizo nuevo amasadero, cocina y despensa, posiblemente para agasajar con altura a sus invitados. Todo ello a cargo de los sirvientes indígenas que se hallaban instalados entre las huertas del solar.

La presencia de estos últimos es evidente y, a pesar de su condición de "sumisos", es posible observar su capacidad de interactuar y negociar su identidad ante el dominio del otro. La "difusión" del ideal social colonial, de sus normas, hábitos y costumbres, y su expresión a través de la ciudad ideal con una Plaza Mayor desde la cual se comunicaba, se vio interrumpida en su núcleo mismo, como en este espacio de la "Casa de los Comuneros II" colindante con dicha plaza. Los indígenas lograron mantener algunas de 


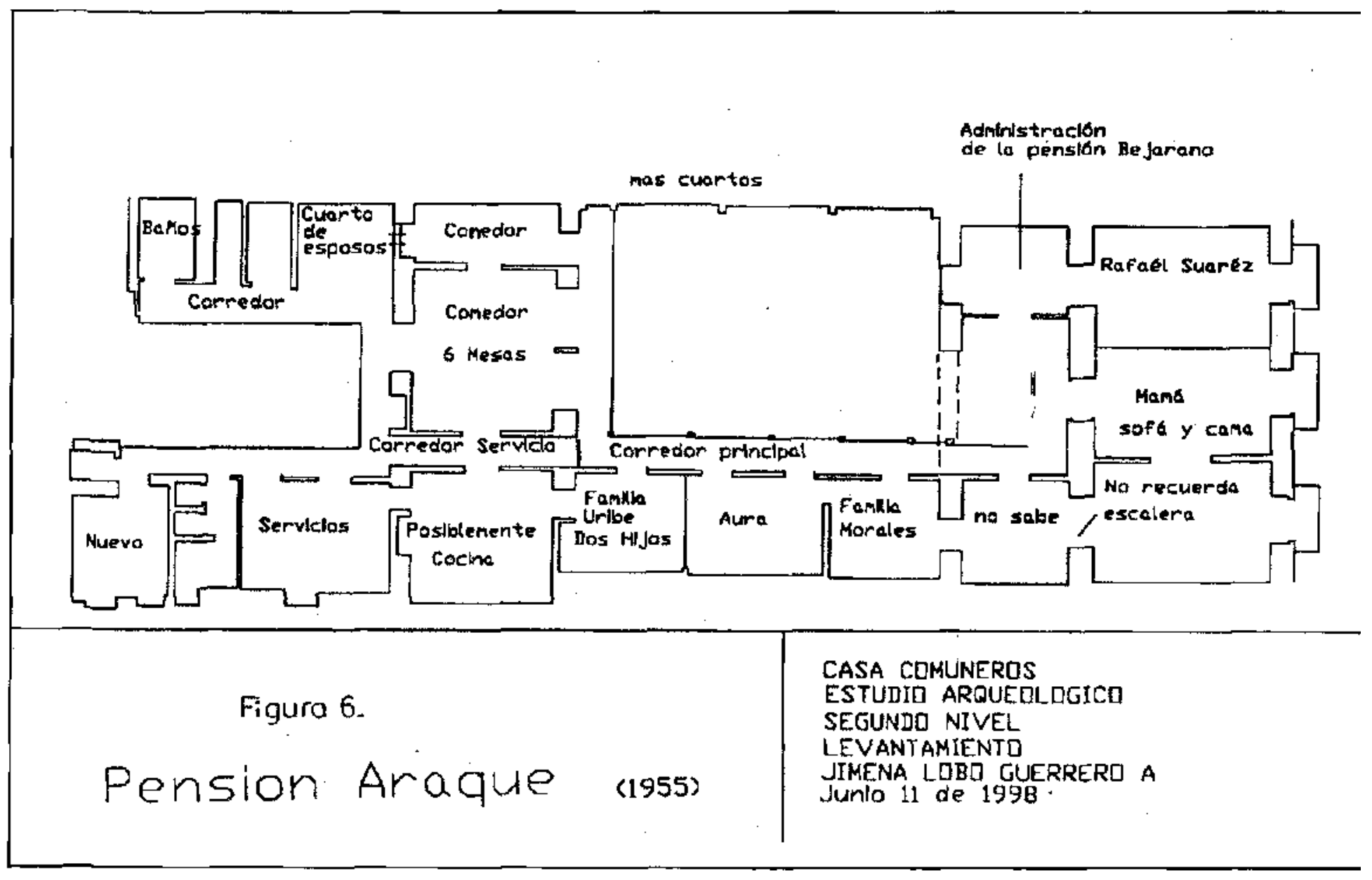


sus expresiones mientras que otras, sin demora, fueron apropiadas, adaptadas y puestas en uso.

Lo que se observa como resultado de las remodelaciones que efectuó Flórez de Ocáriz en su casa, muestra que la evolución en la división de los solares en la ciudad, no siguió un sentido único (dividiéndolos de norte a sur, o de este a oeste). Por el contrario, en la Casa de los Comuneros se evidencia que las actividades que se desarrollaron en las calles colindantes al solar, eran esenciales para decidir sobre cuál de ellas se desarrollarían los espacios más importantes de la casa: las "oficinas" o áreas de recibo de la visita, los balcones desde los cuales se podían observar los diferentes eventos, las tiendas, así como la construcción de las dos nuevas casas. Es así que sobre la calle del Divorcio (hoy calle décima) pasarían las procesiones de las comunidades de la Concepción y de Santa Inés, y en ellas se concentrarían las personas que alquilaban las tiendas para participar en ellas, o de las actividades en la Plaza Mayor (acceso a la pila de agua, mercado, asuntos político-administrativos y de reunión entre los vecinos). Tomando como eje la calle mencionada, el desarrollo del solar, siguió hacia el sur, y en las inmediaciones del predio de la "Casa de los Comuneros II", se ubicaron las áreas de servicio.

Todos estos cambios posiblemente se realizaron hacia 1650, aproximadamente, cuando Flórez de Ocariz decide darle un aspecto más noble a su casa y, con ello, a la esquina suroccidental de la Plaza, modelo de "inspiración" del régimen colonial. Esto también coincide con los planteamientos de Vargas Lesmes, ${ }^{60}$ en cuanto a que sólo hasta la segunda mitad del siglo XVII la Bogotá colonial adquirió su configuración definitiva, de ciudad damero y con las instituciones en marcha, luego de lo cual vivió un proceso de letargo, o de consolidación, que duró hasta fines del siglo XVIII, aunque en términos de la Casa de los Comuneros, ésta se mantuvo sin mayores alteraciones hasta el siglo XIX.

Una segunda interpretación que se desprende de lo anterior, se refiere a las características del solar antes de que lo adquiriera Flórez. La casa que allí existía, de propiedad de Pedro Díaz y Ana de Mendoza, ${ }^{61}$ por lo visto fue

${ }^{60}$ Julián Vargas Lesmes, La sociedad de Santa Fé Colonial, 1990.

61 Flórez de Ocáriz cuando los menciona no los identifica con el título de don o doña, como sí lo hace con las vecinas de sus dos casas nuevas. Para ampliar esta información remitirse a Jaime Jaramillo, Ensayos de historia social, tomo I: La Sociedad Neogranadina, Bogotá, Tercer Mundo Editores, 1989, p. 191. 
apenas un sitio de habitación mediocre para los gustos y exigencias de alguien como Flórez de Ocáriz, dados los mil cien pesos, fuerte suma de dinero, que invirtió en mejorarla. Se refuerza una vez más la tesis de que este sector de la ciudad no se había desarrollado sino muy parcialmente, y es posible que con el advenimiento del genealogista, adquiriera algo más de vida e importancia para la ciudad, y le confería a él el prestigio necesario para distinguirse entre los demás.

Posteriormente, el predio cumple con su ciclo de fraccionamiento. Este se origina en la Colonia, principalmente a través de la división de los espacios de acuerdo a las actividades que se desarrollaron en ellos, como lo señala Vargas Lesmes:

"...los distintos solares de que se componía la casa, los cuales estaban destinados a distintos usos (huerta, etc.), se encontraban separados por tapias de menor altura que las que rodeaban la casa y sustentadas en 'cimientos de piedra aguja', y señalaban un principio de loteo de la propiedad, debido a las distintas funciones que adquirían, así como eran patrón de segregación social dentro del conjunto de la vivienda." 62

El fraccionamiento del solar, efectuado durante la segunda década del siglo XIX, período en el cual se observa el mayor desarrollo del sector y un auge en la economía nacional, es significativo. Ya no se trata del área de servicios de la casa principal esquinera, sino que se convierte en un inmueble independiente. Esto conlleva el cambio en la dirección del desarrollo de los espacios, de norte-sur a oriente-occidente, y coincide con el incremento de las actividades y ámbitos que se concentraron en la calle por la cual se tiene acceso (hoy carrera octava), tales como el Observatorio y el Teatro, entre otros. La autonomía implica concebir los espacios adecuados para satisfacer las nuevas necesidades, de carácter comercial (primer piso) y de vivienda (segundo piso), en el marcado estilo republicano de la época. El impacto que causa este cambio en la estructura existente es profundo, sin embargo, los materiales y la cimentación nueva que la soportan son de mala calidad, lo cual muestra cierta pobreza, no sólo estructural sino en los presupuestos

${ }^{62}$ Julián Vargas Lesmes, La Sociedad, p. 137. 
para su ejecución, sin embargo, éstos se lograron maquillar bien con la variada gama de papel tapiz encontrado y las yeserías en los techos.

De otra parte, el material cultural también evidencia cambios en los gustos de la población, no sólo en el estilo estético de la vivienda, sino en los hábitos alimenticios y los enseres necesarios o preferidos para su consumo. Aunque por la topografía regional se dificulta el acceso a esa inmensa cantidad de artículos que ya circulaba por Occidente se observa que, de una u otra manera, se allegaban a ellos: loza, telas, vino, alimentos, cuero, etc. Sin embargo, la presencia de loza asociada a la tradición indígena, demuestra que no todos los segmentos de la población podían adquirir estos objetos importados, para ellos se mantuvo en circulación estos productos más asequibles.

Por último, las modificaciones hechas a la casa en el presente siglo, involucran especialmente mejoras en los servicios sanitarios, lo cual se evidencia por la multiplicidad de ductos de agua, localizados en uno de los estratos más recientes de la secuencia. La dirección y cantidad de estos ductos es bastante caprichosa, pero además pobremente elaborados. Aunado a ésto, está el fraccionamiento interno de la casa, lo que indica ya su uso por parte de varias familias o grupos de individuos, a los cuales se les satisfacen sus necesidades con la incorporación de los ductos. Al parecer, el cambio más reciente se relaciona con los pisos, los cuales son transformados y hechos casi enteramente de cemento, posiblemente en busca de una mejor higiene y para facilitar su aseo.

El contraste de la información deja entrever, a través de los diferentes elementos de la cultura material (arquitectónicos, arqueológicos y documentales), un esbozo de las configuraciones sociales que pueden estar representadas en los materiales. Más aún, a pesar de que el predio estudiado perteneció en una época a uno de los personajes de la élite santafereña, es posible, a través de diferentes recursos, obtener evidencias de los otros grupos sociales que formaron parte del ámbito de la ciudad, y cuyas historias poco se conocen. El contacto es evidente, las rupturas en la implantación del modelo "ideal" de sociedad-ciudad del régimen colonial también, pero sólo con la incorporación de mayores evidencias a través de otros proyectos se podrán construir estas nociones de una manera más sólida, por lo que se reitera que el estudio del patrimonio es una excelente base para demostrarlas. El contraste de los datos estudiados por las diferentes disciplinas, más que la hegemonía de una de ellas, conduce igualmente a construir nuevas historias sobre la sociedad y la cultura. 
HISTORIA DEL PATRIMONIO CULTURAL

\section{BIBLIOGRAFIA}

Acuarelas de Mark, 1843-1856, Bogotá, Litografía Arco, 1992.

Aguilera Peña, Mario, Insurgencia urbana en Bogotá, Bogotá, Colcultura, 1997.

Aprile-Gniset, Jacques, La ciudad colombiana. Prehispánica, de conquista e indiana, Bogotá, Biblioteca Banco Popular, 1991.

Carandini, Andrea, Historias en la Tierra, Barcelona, Editorial Crítica, 1997.

Cifuentes, A. y L. Moreno, Proyecto de rescate arqueológico de la avenida Villavicencio (Barrio Candelaria La Nueva-Bogotá), Informe Instituto Colombiano de Antropología-ICAN (inédito), 1987.

Cochrane, Stuart, Viajes por Colombia, 1823-1824, Bogotá, Banco de la República, 1994 [1825].

Cordovez Moure, José María, Reminiscencias de Santafé y Bogotá, 6 tomos, Bogotá, Gerardo Rivas Editor, 1991 [1893-1900].

Coysh, A.W. \& R.K. Henrywood, Blue and White Printed Pottery, 1780-1880, Vol.I, Londres, Antique Collectors Club, (6a. Ed.), 1997.

De la Rosa, Moisés, Calles de Santafé de Bogotá. Homenaje en su IV Centenario, Bogotá, Ediciones del Concejo, 1938.

Deagan, Kathleen, Historical Archaeology, vol. 3, 1998.

Deetz, James, In Small Things Forgotten, Nueva York, Anchor Books, 1996.

González, Marta Cecilia, Estudio histórico de la "Casa de los Comuneros II", Informe manuscrito, 1998.

Hamilton John R, Viajes por el interior de las provincias de Colombia, Bogotá, Banco de la República, 1993 [1827].

Harris, Edward, Principios de estratigrafía arqueológica, Barcelona, Editorial Crítica, 1991. 
Historia de Bogotá, Tomos I y II, Bogotá, Fundación Misión Colombia, Editorial Villegas, 1988.

Holton, Isaac, La Nueva Granada. Veinte meses en los Andes, Bogotá, Banco de la República, 1981 [1857].

Ibáñez, Pedro M., Crónicas de Bogotá, Tomo IV, Bogotá, Academia de Historia de Bogotá, Tercer Mundo, 1989 [1951].

Instituto del Patrimonio Cultural (IPC-Venezuela), Identificación y fechado de cerámicas coloniales, Caracas, Manual elaborado por el IPC y Kathleen Deagan, 1997.

Jaramillo Uribe, Jaime, Ensayos de historia social. Tomo I: La Sociedad Neogranadina, Bogotá, Tercer Mundo Editores, 1989.

Lamus, Marina, Teatro en Colombia: 1831-1886, Bogotá, Editorial Ariel, 199?..

Lomné, Georges, "Las ciudades de la Nueva Granada: teatro y objeto de los conflictos de la memoria política (1810-1830)", Anuario Colombiano de Historia Social y de la Cultura, No.21, Bogotá, 1993.

Martínez Carreño, Aída, Mesa y cocina en el siglo XIX, Bogotá, Fondo Cultural Cafetero, 1985.

Martínez, Carlos, Santqfé. Capital del Nuevo Reino de Granada, Bogotá, Fondo de Promoción de la Cultura, 1987.

Mollien, Gaspard T., Viaje por la República de Colombia en 1823, Bogotá, Banco de la República, 1992.

Ocampo, José Antonio, Colombia y la economía mundial, 1830-1910, Bogotá, TM Editores, 1998.

Ortega Díaz, Alfredo, Arquitectura de Bogotá, Bogotá, Proa, 1988 [1924].

Ortega Ricaurte, Daniel, Cosas de Santafe de Bogotá, Bogotá, Academia de Historia, Tercer Mundo, 1990 [1959]. 
Ortega Ricaurte, Enrique, "Testamento de don Juan Florez de Ocáriz", Boletín de Historia y Antigüedades, Vol. XV, 1940.

Pratt, Mary Louise, Imperial Writing. Travel Writing and Transculturation, Londres, Routledge, 1992.

Salcedo, Jaime, Urbanismo hispanoamericano, siglos XVI, XVII y XVIII, Bogotá, Centro Editorial Javeriano, (2a. Ed), 1996.

Schavelson, Daniel, Catálogo de cerámicas históricas del Río de La Plata, Centro de Arqueología Urbana, Universidad de Buenos Aires, (S.f.).

Silva, Ricardo, "El remiendito", Cuadros de Costumbres, Cali, Carvajal y Cía., 1969 [c. 1860].

The Victorian Catalogue of Household Goods, Londres, Studio Editions, 1991 [1883].

Therrien, Monika, "Sociedad y cultura material de la Nueva Granada ¿Preferencias o referencias? Aportes de la Arqueología Histórica en Colombia", Revista Colombiana de Antropología, vol. XXXIII, Bogotá, Instituto Colombiano de Antropología, 1997, pp. 5-51.

Vargas Lesmes, Julián, La sociedad de Santa Fe colonial, Bogotá, CINEP, 1990.

Vergara y Vergara, Jose Ma., "Las tres tazas", Cuadros de Costumbres, Cali, Carvajal y Cía., 1969 [c. 1870]. 